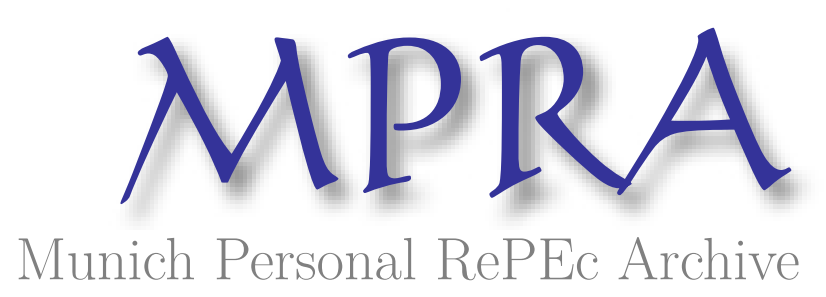

\title{
Immigration, Skill Heterogeneity and Qualification Mismatch
}

Liu, Xiangbo and Palivos, Theodore and Zhang, Xiaomeng

Renmin University of China, Athens University of Economics and Business, Renmin University of China

16 August 2014

Online at https://mpra.ub.uni-muenchen.de/57981/

MPRA Paper No. 57981, posted 18 Aug 2014 10:06 UTC 


\title{
Immigration, Skill Heterogeneity and Qualification Mismatch
}

\author{
Xiangbo Liu \\ Theodore Palivos* \\ Renmin University of China \\ Athens University of Economics and Business
}

\author{
Xiaomeng Zhang \\ Renmin University of China
}

August 17, 2014

\begin{abstract}
We investigate the effects of US immigration on native workers in a search and matching environment that allows for skill heterogeneity, differential search cost, cross-skill matching and imperfect transferability of human capital across borders. We find that cross-skill matching benefits the unskilled and hurts the skilled native workers. Similarly, new unskilled immigration benefits the low-skilled native workers and hurts the high-skilled. On the other hand, new skilled immigration benefits both skilled and unskilled natives. Moreover, when we simulate the effects of the actual US immigration influx that took place between the years 2000 and 2009, we find that both skilled and unskilled native workers gain. We also find that initially an improvement in the transferability of human capital benefits the high-skilled natives at the expense of the low-skilled. Nevertheless, below a certain overeducation ratio, further improvements in the transferability of human capital make both types of native workers worse off.
\end{abstract}

JEL Classification: F22, J61, J64

Keywords: Immigration, Search and Matching, Skill Heterogeneity, Occupational Mismatch, Overeducation, Transferability of Human Capital

${ }^{*}$ Corresponding Author: Department of Economics, Athens University of Economics and Business, 76 Patission Str., GR104 34, Athens, Greece. E-mail: tpalivos@aueb.gr, Tel: +30210 8203346. 


\section{Introduction}

Recent data show that a substantial number of workers are mismatched (see Leuven and Oosterbeek, 2011). Moreover, the majority of them are overeducated, i.e., they have more education than what their job requires. ${ }^{1}$

Ever since Richard Freeman's controversial book "The Overeducated American" (Freeman, 1976), labor market mismatch, and especially overeducation, has constantly been in the research agenda of labor economists. ${ }^{2}$ A number of hypotheses have been put forward to explain labor mismatch and overeducation in particular. A recently developed strand of the literature is based on the search and matching approach of the labor market (e.g., Diamond, 1982; Mortensen and Pissarides, 1994). Accordingly, the labor market does not clear instantaneously and qualification or skill mismatch is an outcome of frictions. Workers and firms search for trading partners and, since the matching technology is imperfect, skilled or highly educated workers may end up in unskilled jobs for which they are overeducated or overqualified. In a paper by Albrecht and Vroman (Albrecht and Vroman, 2002), one of the first in this literature, high-skilled workers can be permanently mismatched with low-skill jobs. Gautier (2002) and Dolado, Jansen and Jimeno (2009) allow for on-the-job search conducted by mismatched workers, which makes any such skill mismatches transitory; that is, initially high-skilled workers accept low-skill jobs but then climb the occupational ladder through on-the-job search. ${ }^{3}$ Finally, Chassamboulli (2011) develops a similar model to match some of the business cycle properties of labor market variables.

Qualification mismatch is an even more prominent feature among immigrants (see, among others, Chiswick and Miller, 2009, and Beckhusen, Florax, Poot and Waldorf, 2013, for the US; Chiswick and Miller, 2010, for Australia and comparisons with the US and Canada; Aleksynska and Tritah, 2013, and Nieto, Matano and Ramos, 2013, for

\footnotetext{
${ }^{1}$ Leuven and Oosterbeek (2011) report that the average share of overeducated workers over many empirical studies that use data from different countries, over different decades and collected using different methods is 30 percent.

${ }^{2}$ The case where an employee's education or skill level differs from what the job requires is known as "vertical mismatch," e.g., a college graduate works at a position that requires at most a high-school diploma. On the contrary, when the employee's type of education or skill is different from what the job requires then there exists "horizontal mismatch," e.g., an employee works in a field different from the one for which she was trained. In this paper, since there is essentially only one good, we analyze only the case of vertical mismatch. For a comprehensive survey of the overeducation and labor mismatch literature see, among others, Leuven and Oosterbeek (2011).

${ }^{3}$ On-the-job search by overqualified employees and job-to-job transitions are widely observed phenomena in modern labor markets; see the evidence summarized in Dolado et al. (2009).
} 
Europe. ${ }^{4}$ For example, evidence summarized in Piracha and Vadean (2013) shows that the incidence of overeducation among immigrants ranges from 13.2 percent in the case of Bangladeshi in the UK to 58.1 percent in the case of female immigrants residing in New Zealand for less than five years. Moreover, Beckhusen et al. (2013), who analyze the US data between the years 1980-2009, conclude that "overeducation among high-skilled immigrants vastly exceeds that of comparable natives" (p. 834). Also, Aleksynska and Tritah (2013) find that 22 percent of immigrants in Europe are overeducated compared to only 13 percent of the native born.

The literature has identified as one of the main reasons for the higher degree of educational mismatch among immigrants the imperfect transferability of human capital across countries, which may be the result, among others, of lack of language skills, cultural and economic differences between the country of origin and the country of destination and occupational licensing requirements. A plethora of studies have demonstrated for different countries that immigrants earn a lower marginal return on their human capital compared to natives (see Chiswick, 1978; Baker and Benjamin, 1994; Bell, 1997; Constant and Massey, 2003; Longva and Raaum, 2003, to name but a few). Other studies have shown that human capital acquired by immigrants in their country of origin is paid significantly less than human capital acquired in the country of destination (see Friedberg, 2000, and Nielsen, 2007).

This paper studies these issues following the search and matching approach for the analysis of the impact of immigration (see Ortega, 2000; Liu, 2010; Chassamboulli and Palivos, 2013, 2014; Chassamboulli and Peri, 2014; Battisti, Felbermayr, Peri, and Poutvaara, 2014). This approach allows one to analyze the effects of immigration on unemployment and wages that result from the impact of changes in the availability of jobs on the bargaining position of workers. More specifically, we develop a search and matching model along the lines of Albrecht and Vroman (2002), Gautier (2002) and Dolado et al. (2009), to analyze the effects of educational mismatch among immigrants on the labor market outcomes in the host country. To the best of our knowledge, this is the first paper that does this. In particular, first, we study the consequences of cross-skill matching among immigrants, i.e., the presence of mismatched immigrant workers, for natives, both skilled and unskilled. Second, we examine the effects of new skilled and unskilled immi-

\footnotetext{
${ }^{4}$ Piracha and Vadean (2013) present a summary of the findings from the literature on educational mismatch of immigrants.
} 
gration when there is cross-skill matching. Finally, we investigate the results of improving the transferability of human capital across countries.

We calibrate the model to the US economy and find a number of new and interesting results. First, the presence of mismatched workers benefits the unskilled and hurts the skilled native workers. This is so, because cross-skill matching raises the outside option of high-skilled immigrants, which increases their wage and discourages job entry. On the other hand, high-skilled immigrants have a lower outside option than low-skilled natives and hence allowing for cross-skill matching lowers the wage that a low-skill firm expects to pay and spurs entry in the low-skill sector.

Similarly, new unskilled immigration benefits the low-skilled native workers and hurts the high-skilled. Since immigrants have a higher search cost than natives, they are forced to accept lower wages. Hence, an increase in the number of unskilled immigrants reduces the labor cost that a low-skill firm expects to pay. On the other hand, it raises the outside option of mismatched workers (it is easier for them to find a low-skill job) and hence it increases the labor cost that a high-skill firm expects to pay. Consequently, the increase in unskilled immigration induces entry in the low-skill and exit in the high-skill sector. This results in a higher (lower) wage and employment rate for low-skilled (high-skilled) natives.

On the other hand, new skilled immigration benefits both skilled and unskilled natives. Once again, the lower wage received by immigrants, owing to their higher search cost, induces entry and increases the number of jobs in the high-skill sector. This raises the wage and the employment rate of high-skilled natives. It also decreases the number of mismatched high-skilled immigrants and hence benefits the low-skilled natives as well. Moreover, when we simulate the effects of an immigration influx that is of the same magnitude and composition as the one that took place in the US between the years 2000 and 2009, we find that both skilled and unskilled gain from it.

Finally, we show that initially, i.e., for a high overeducation ratio, an improvement in the transferability of human capital across borders benefits the high-skilled natives at the expense of the low-skilled. This takes place because the improvement in the transferability of human capital increases the probability that a high-skilled immigrant will match with a high-skill firm, while at the same time it increases the separation between low-skill firms and high-skilled immigrants (it becomes easier for mismatched immigrants to find jobs in the high-skill sector through on-the-job search and quit their current job in the low- 
skill sector). As a consequence, more (less) firms enter the high-skill (low-skill) sector, which explains why high-skilled natives benefit and low-skilled lose. Nevertheless, below a certain overeducation ratio, further improvements in the transferability of human capital increase the wage of high-skilled immigrants so much that they reverse the flow direction and turn firm entry into exit; thus, both skilled and unskilled native workers become now worse off in terms of wages and employment.

The rest of the paper is organized as follows. Section 2 presents the model and solves for the wages, the unemployment rates and the overeducation ratio. Section 3 analyzes the effects of $a$ ) cross-skill matching, $b$ ) an increase in immigration, and $c$ ) an improvement in the transferability of foreign human capital. Section 4 calibrates the model to the US data and presents simulation results for the changes analyzed theoretically in the aforementioned sections. Finally, Section 5 offers some concluding remarks. There is also an Appendix, which provides detailed proofs of the propositions and performs an extensive sensitivity analysis of our results.

\section{The Model}

This section introduces our dynamic search and matching model with ex-ante heterogeneous agents. Time is continuous. All agents are risk neutral and discount the future at a constant rate $r>0$.

\subsection{The Basic Setup}

Consider an economy inhabited by a continuum of workers who are either natives $(N)$ or immigrants $(I)$ and are indexed by $\kappa \in\{N, I\}$. The measure of native workers is normalized to 1 , while that of immigrants is constant and denoted by $I$. Besides their country of origin, workers differ also with respect to their skills. They are either highskilled (also referred to simply as skilled) or low-skilled (unskilled). We use the index $i$ to distinguish their skill level, $i \in\{H, L\}$, where $H$ stands for high- and $L$ for low-skilled. The share of high-skilled workers in the native population is represented by $\lambda \in(0,1)$; thus, $1-\lambda$ is the fraction of native workers that are low-skilled. Similarly, the measures of high-skilled and low-skilled immigrants are denoted by $I_{H}$ and $I_{L}$, respectively.

There is also a large continuum of firms. Each firm can have at most one job, which is suited either for a skilled $(H)$ or for an unskilled $(L)$ worker. We use the index $j$ to 
distinguish between the two types of jobs, $j \in\{H, L\}$. Firms must decide ex ante, that is, before searching for a worker, whether they will open a skilled or an unskilled job. For simplicity, we assume that creating a vacancy is costless, although this can be easily amended following, for example, Laing, Palivos and Wang (1995, 2003). A skilled job can be filled only by a skilled (native or immigrant) worker. The flow of output produced by such a pair is $y_{H}$. By contrast, an unskilled job, one that needs no special skill, can be filled by an unskilled (native or immigrant) worker whose constant flow of productivity in this type of job is $y_{L}$. Moreover, as mentioned in the Introduction, empirical evidence typically suggests that educational mismatch is pronounced for immigrants in the labor market of the host countries. To account for this, we assume that an unskilled job can also be occupied by a skilled immigrant. ${ }^{5}$ Moreover, the productivity of a skilled immigrant in an unskilled job is $\mu y_{L}$ with $\mu \geq 1 .^{6}$

\subsection{Search and Matching}

Each firm posts either a skilled or an unskilled vacancy and incurs a flow $\operatorname{cost} c_{j}, j=H, L$, until the vacancy is filled. Free entry determines endogenously the number of firms in each labor market. On the other hand, unemployed workers search for employment. In particular, skilled native workers direct their search towards the skilled labor market, whereas unskilled natives and immigrants search for unskilled jobs. Finally, as mentioned above, skilled immigrants search for jobs in both markets. We also allow for on-the-job search by skilled immigrants who have been matched with unskilled vacancies (mismatched workers). A mismatched skilled immigrant worker can therefore move to a better job without an intervening spell of unemployment, i.e., skilled immigrants may experience job-to-job transition.

During unemployment, workers receive a flow of income $b_{i}<y_{i}$, which captures the opportunity cost of employment, e.g., the payoff from home production, leisure, and unemployment benefits. Moreover, job seekers incur a cost of searching for a job, $h^{\kappa}$, $\kappa=N, I$. In general, one expects $h^{N}<h^{I}$, since immigrants face a higher search cost than natives when they search in a foreign country (see also Ortega 2000 and Chassamboulli and

\footnotetext{
${ }^{5}$ In other words, to simplify the analysis, we assume that there is a social stigma against native skilled workers who occupy unskilled jobs. We note, however, that, at the expense of simplicity, this result can be derived endogenously given that, as we assume below, skilled native and immigrant workers have the same productivity but different search cost.

${ }^{6}$ Gautier (2002) assumes that $\mu$ can be on either side of unity, whereas Belan, Carré and Gregoir (2010) assume essentially that $\mu \geq 1$.
} 
Palivos 2014, who make the same assumption). Without loss of generality we normalize $h^{N}$ to zero. Of course, having a job helps immigrants to get assimilated and gives them access to a network associated with that job. For these reasons, we assume that a mismatched worker who conducts on-the-job search bears a lower cost than an unemployed skilled immigrant worker. More specifically, the search cost for a mismatched worker is $\eta h^{I}$, where $\eta \in[0,1]$. Thus, all five types of job seekers have different net income. ${ }^{7}$ Unemployed skilled and unskilled native workers have income $b_{i}, i=H, L$ and zero search cost, unemployed skilled and unskilled immigrant workers have income $b_{i}$ and search cost $h^{I}$ and mismatched skilled immigrant workers have income equal to their wage $w_{H L}^{I}$ and search cost $\eta h^{I}$.

Job seekers and vacant jobs are matched randomly in a pair-wise fashion. As in Gautier (2002) and Belan, Carré and Gregoir (2010), search is directed. The matching function in the unskilled labor market is $M\left(v_{L}, u_{L}^{N}+u_{L}^{I}+u_{H}^{I}\right)$, where $v_{L}$ is the mass of unskilled vacancies and $u_{i}^{\kappa}$ denotes the mass of unemployed workers of skill type $i=H, L$ and origin $\kappa=N, I$. Similarly, the matching function in the skilled labor market is $M\left(v_{H}, u_{H}^{N}+u_{H}^{I}+\right.$ $\left.e_{H L}^{I},\right)$, where $v_{H}$ is the mass of skilled vacancies and $e_{H L}^{I}$ is the mass of mismatched skilled immigrant workers; the latter continue to search on the job for better employment. The matching functions $M(\cdot)$ are assumed to be twice continuously differentiable, strictly increasing and strictly concave with respect to each of their arguments, exhibit constant returns to scale and satisfy standard Inada conditions.

We define the labor market tightness in the unskilled labor market as $\theta_{L}=v_{L} /\left(u_{L}^{N}+\right.$ $\left.u_{L}^{I}+u_{H}^{I}\right)$ and in the skilled as $\theta_{H}=v_{H} /\left(u_{H}^{N}+u_{H}^{I}+e_{H L}^{I}\right)$. The rate at which low-skill vacancies are filled is $q\left(\theta_{L}\right)=M_{L} / v_{L}$, where $M_{L}$ denotes the matches in the unskilled labor market and $q^{\prime}\left(\theta_{L}\right)<0$. The rate at which unemployed low-skilled (native or immigrant) workers and high-skilled immigrants find low-skill jobs is $m\left(\theta_{L}\right)=\theta_{L} q\left(\theta_{L}\right)$, where $m^{\prime}\left(\theta_{L}\right)>0$.

On the other hand, a match between a high-skill vacancy and a skilled immigrant worker may not be consummated due to the fact that foreign human capital may not be easily transferable in the host country. As mentioned in the Introduction, this may be due to lack of language skills, lack of information regarding the education system in the immigrant's home country, cultural differences, licensing requirements, etc. We capture this by allowing the transition rates from unemployment to employment for immigrant and native skilled workers to differ. In particular, the rate at which unemployed high-

\footnotetext{
${ }^{7}$ As we show below, even all types of employed workers have different income.
} 
skilled native workers find high-skill jobs is $m\left(\theta_{H}\right)=\theta_{H} q\left(\theta_{H}\right)$, where $m^{\prime}\left(\theta_{H}\right)>0$, whereas the corresponding rate for high-skilled immigrant workers is lower and equal to $\gamma m\left(\theta_{H}\right)$, $\gamma<1$. The parameter $\gamma$ is meant to capture imperfect transferability of human capital across borders. ${ }^{8}$

We also assume that all matches dissolve at an exogenous rate $s_{j}$, which is specific to their type. Nevertheless, the total turnover of mismatched workers has one more component, $\gamma m\left(\theta_{H}\right)$, which is endogenous. In other words, since mismatched workers conduct on-the-job search, a match between a skilled immigrant and a low-skill job dissolves either because the job is destroyed by a shock or because the worker decides to quit and work for a high-skill job. The former occurs at a rate $s_{L}$ and the latter at a rate $\gamma m\left(\theta_{H}\right)$; hence, for this and only this type of matches, the total separation rate is $s_{L}+\gamma m\left(\theta_{H}\right)$.

\subsection{Asset Values}

In general, we let $\Pi$ and $V$ be the values associated with a filled and an unfilled vacancy and $E$ and $U$ the values associated with an employed and an unemployed worker, respectively. More specifically, we let $\Pi_{i j}^{\kappa}$ be the present discounted value associated with a firm of type $j$ that is matched with a worker of skill $i$ and origin $\kappa .^{9}$ Then in steady state:

$$
\begin{gathered}
r \Pi_{i j}^{\kappa}=y_{i}-w_{i j}^{\kappa}-s_{j}\left(\Pi_{i j}^{\kappa}-V_{j}\right), \quad \text { if } i=j=H, L, \text { and } \kappa=N, I, \\
r \Pi_{H L}^{I}=\mu y_{L}-w_{H L}^{I}-\left[s_{L}+\gamma m\left(\theta_{H}\right)\right]\left(\Pi_{H L}^{I}-V_{L}\right)
\end{gathered}
$$

where $w_{i j}^{\kappa}$ is the wage rate of a worker who has skill $i=H, L$ and origin $\kappa=N, I$ and is matched with a position of type $j=H, L$ and $V_{j}$ is the value associated with a type $j$ unfilled (vacant) position. Notice that although skilled immigrant workers in an unskilled job can be more productive than unskilled immigrant or native workers (if $\mu>1)$, their job separation rate is also higher $\left(s_{L}+\gamma m\left(\theta_{H}\right)>s_{L}\right)$. This is because skilled immigrant workers in an unskilled job continue to search for a skilled position. Overall, it is ambiguous which of the two types of workers will result in a higher profit for the firm.

\footnotetext{
${ }^{8}$ The fact that, compared to natives, the probability of a match is lower only for skilled immigrants, and not for unskilled, supports our idea that $\gamma<1$ captures the imperfect transferability of foreign human capital instead of, for example, the existence of discrimination.

${ }^{9}$ It may be recalled that high-skill positions can be filled only with high-skilled workers but low-skill positions can be filled either by low-skilled workers (natives or immigrants) or by high-skilled immigrants; hence, there are five possible combinations: $\Pi_{L L}^{N}, \Pi_{H H}^{N}, \Pi_{L L}^{I}, \Pi_{H H}^{I}, \Pi_{H L}^{I}$.
} 
The expected income streams accrued to unfilled vacancies of type $j=H, L$ are given by

$$
\begin{gathered}
r V_{H}=-c_{H}+q\left(\theta_{H}\right)\left[\phi_{H H}^{N} \Pi_{H H}^{N}+\left(1-\phi_{H H}^{N}\right) \gamma \Pi_{H H}^{I}-V_{H}\right], \\
r V_{L}=-c_{L}+q\left(\theta_{L}\right)\left[\phi_{L L}^{N} \Pi_{L L}^{N}+\phi_{L L}^{I} \Pi_{L L}^{I}+\left(1-\phi_{L L}^{N}-\phi_{L L}^{I}\right) \Pi_{H L}^{I}-V_{L}\right],
\end{gathered}
$$

where $\phi_{i j}^{\kappa}$ represents the probability that a vacancy of type $j$ meets a worker of skill $i$ and of origin $\kappa$. More specifically,

$$
\phi_{H H}^{N}=\frac{u_{H}^{N}}{u_{H}^{N}+u_{H}^{I}+e_{H L}^{I}}, \quad \phi_{L L}^{N}=\frac{u_{L}^{N}}{u_{L}^{N}+u_{L}^{I}+u_{H}^{I}}, \quad \phi_{L L}^{I}=\frac{u_{L}^{I}}{u_{L}^{N}+u_{L}^{I}+u_{H}^{I}} .
$$

We turn next to the asset values associated with the workers. The expected income streams accrued to employed workers are given by

$$
\begin{gathered}
r E_{i j}^{\kappa}=w_{i j}^{\kappa}-s_{j}\left(E_{i j}^{\kappa}-U_{i}^{\kappa}\right), \quad \text { if } i=j=H, L \text { and } \kappa=N, I, \\
r E_{H L}^{I}=w_{H L}^{I}-\eta h^{I}-s_{L}\left(E_{H L}^{I}-U_{H}^{I}\right)+\gamma m\left(\theta_{H}\right)\left(E_{H H}^{I}-E_{H L}^{I}\right) .
\end{gathered}
$$

In particular, equation (7) gives the flow income accrued to a skilled immigrant worker in an unskilled position, i.e., a mismatched worker. The last term on the right-hand side (RHS) gives the change in this value because of the on-the-job search option. We also assume that wages are constantly renegotiated at no cost. Hence, in the end, the outside option of a mismatched worker coincides with that of an unemployed. This implies that the wage of a skilled immigrant who matches with a skilled job is independent of the worker's previous employment status, that is, at skilled jobs unemployed and mismatched immigrants receive the same wage $w_{H H}^{I}$ (for further details see Gautier, 2002, and Dolado et al., 2009, who make the same assumption).

Similarly, the values associated with unemployed workers are:

$$
\begin{gathered}
r U_{i}^{N}=b_{i}+m\left(\theta_{i}\right)\left(E_{i j}^{N}-U_{i}^{N}\right), \quad \text { if } i=j=H, L, \\
r U_{L}^{I}=b_{L}-h^{I}+m\left(\theta_{L}\right)\left(E_{L L}^{I}-U_{L}^{I}\right), \\
r U_{H}^{I}=b_{H}-h^{I}+m\left(\theta_{L}\right)\left(E_{H L}^{I}-U_{H}^{I}\right)+\gamma m\left(\theta_{H}\right)\left(E_{H H}^{I}-U_{H}^{I}\right) .
\end{gathered}
$$


Finally, we assume free entry in establishing either type of vacancy. Thus, in equilibrium, the expected payoff of posting a vacancy is equal to zero, that is,

$$
V_{j}=0, j=H, L
$$

\subsection{Wage Determination}

Once a worker meets a firm, they bargain over the wage rate. They essentially solve a generalized Nash bargaining problem given by

$$
\underset{w_{i j}^{\kappa}}{\operatorname{aax}}\left(E_{i j}^{\kappa}-U_{i}^{\kappa}\right)^{\beta}\left(\Pi_{i j}^{\kappa}-V_{j}\right)^{(1-\beta)}
$$

where $E_{i j}^{\kappa}-U_{i}^{\kappa}$ and $\Pi_{i j}^{\kappa}-V_{j}$ are the worker's and the firm's surpluses from the match, respectively. Moreover, $\beta \in(0,1)$ denotes the worker's and $1-\beta$ the firm's bargaining strength. The firm and the worker jointly seek to find the wage $w_{i j}^{\kappa}$ that solves the aforementioned problem. The solution gives

$$
(1-\beta)\left(E_{i j}^{\kappa}-U_{i}^{\kappa}\right)=\beta\left(\Pi_{i j}^{\kappa}-V_{j}\right)
$$

In other words, the worker gets a share $\beta$ and the firm $1-\beta$ of the total surplus $S_{i j}^{\kappa}=$ $\Pi_{i j}^{\kappa}+E_{i j}^{\kappa}-V_{j}-U_{i}^{\kappa}$ generated from a match. Then, by using the above asset value equations, we can derive the expressions for the wage rates $w_{i j}^{\kappa}$.

Substituting for $E_{i j}^{\kappa}-U_{i}^{\kappa}$ and $\Pi_{i j}^{\kappa}$, using equations (1)-(10), in equation (12) and noting that $V_{j}=0$ (equation 11 ), we find

$$
\begin{gathered}
w_{i j}^{N}=\frac{\beta\left[r+s_{j}+m\left(\theta_{i}\right)\right] y_{i}+(1-\beta)\left(r+s_{j}\right) b_{i}}{\Psi\left(\theta_{i}\right)}, \quad \text { if } i=j=H, L, \\
w_{L L}^{I}=\frac{\beta\left[r+s_{L}+m\left(\theta_{L}\right)\right] y_{L}+(1-\beta)\left(r+s_{L}\right)\left(b_{L}-h^{I}\right)}{\Psi\left(\theta_{L}\right)} \\
=w_{L L}^{N}-\frac{(1-\beta)\left(r+s_{L}\right)}{\Psi\left(\theta_{L}\right)} h^{I}, \\
w_{H L}^{I}=\frac{\beta\left[r+s_{L}+m\left(\theta_{L}\right)+\gamma m\left(\theta_{H}\right)\right] \mu y_{L}+(1-\beta)\left[r+s_{L}+\gamma m\left(\theta_{H}\right)\right]\left[b_{H}-(1-\eta) h^{I}\right]}{\Psi\left(\theta_{L}\right)+\gamma m\left(\theta_{H}\right)},
\end{gathered}
$$




$$
w_{H H}^{I}=\frac{\beta\left[r+s_{H}+\gamma m\left(\theta_{H}\right)\right] y_{H}+(1-\beta)\left(r+s_{H}\right)\left[b_{H}-h^{I}+\frac{\beta m\left(\theta_{L}\right)\left\{\mu y_{L}-\left[b_{H}-(1-\eta) h^{I}\right]\right\}}{\Psi\left(\theta_{L}\right)+\gamma m\left(\theta_{H}\right)}\right]}{\Psi\left(\theta_{H}\right)-(1-\gamma) \beta m\left(\theta_{H}\right)},
$$

where $\Psi\left(\theta_{i}\right) \equiv r+s_{j}+\beta m\left(\theta_{i}\right), i=j=H, L$. In each case, the wage is basically a combination of the worker's outside option and job productivity.

Comparing the wages for skilled and unskilled native workers (equation 13), we see that, ceteris paribus, the difference $w_{H H}^{N}-w_{L L}^{N}$ depends positively on the difference between the workers' productivities $y_{H}-y_{L}$ and their outside of employment income $b_{H}-b_{L}$ and negatively on the difference in the probabilities of losing their jobs, i.e., the separation rates $s_{H}-s_{L}$. It is expected that $y_{H}>y_{L}, b_{H}>b_{L}$ and $s_{H}<s_{L}$ and hence $w_{H H}^{N}>w_{L L}^{N}$. Moreover, it follows from equation (14) that unskilled immigrant workers receive a lower wage than unskilled natives $\left(w_{L L}^{I}<w_{L L}^{N}\right)$, despite the fact that they are equally productive. This occurs because immigrants face a higher search cost $\left(h^{I}>0=h^{N}\right)$, which forces them to accept lower wages.

Next, we compare the difference between the wage of an unskilled immigrant worker $w_{L L}^{I}$, given by equation (14), with that of a mismatched worker (a skilled immigrant worker who works in an unskilled job) $w_{H L}^{I}$, which is given by equation (15). There are three sources of differentiation between the two wages. First, mismatched immigrants have a higher separation rate than unskilled immigrants $\left(s_{L}+\gamma m\left(\theta_{H}\right)>s_{L}\right)$. This lowers the size of the expected surplus generated from a match between a skilled immigrant and an unskilled job, which leads to a lower wage for mismatched workers. Second, mismatched workers can be more productive (if $\mu>1$ ), which raises their wage. Third, the two types of workers have different outside options, which affect their bargaining positions, $b_{H}-(1-\eta) h^{I}$ vis-à-vis $b_{L}-h^{I}$. Assuming that $b_{H}>b_{L}>b_{L}-\eta h^{I}$, this effect also raises the difference between the two wages, $w_{H L}^{I}-w_{L L}^{I}$. Nevertheless, the overall effect is ambiguous; in other words, either of the two wages can be higher than the other. In fact, one can find the value of $\mu$ that equates the two wages or the two surpluses, as in Gautier (2002).

Finally, let us compare the wage of a skilled immigrant who is matched with a highskill position $\left(w_{H H}^{I}\right)$ with the wage of a native counterpart $\left(w_{H H}^{N}\right)$; compare equation (13) for $i=j=H$ with equation (16). There are two opposing channels. On the one hand, immigrants are subject to higher search costs $\left(h^{I}>0=h^{N}\right)$ and they face a lower job 
finding rate (because of the low transferability of foreign human capital, which results in $\gamma<1$ ). Both of these effects lower immigrants' bargaining position and hence their wage $\left(w_{H H}^{I}<w_{H H}^{N}\right)$. On the other hand, skilled immigrants have the opportunity to fill an unskilled job, which raises their bargaining position and their wage rate in tandem $\left(w_{H H}^{I}>w_{H H}^{N}\right)$.

\subsection{Steady-State Composition of the Labor Force}

The following definitions apply regarding the different sub-groups in the labor force:

$$
\begin{aligned}
u_{H}^{N}+e_{H H}^{N} & =\lambda, \\
u_{L}^{N}+e_{L L}^{N} & =1-\lambda, \\
u_{H}^{I}+e_{H L}^{I}+e_{H H}^{I} & =I_{H}, \\
u_{L}^{I}+e_{L L}^{I} & =I_{L},
\end{aligned}
$$

where, following our previous notation, $e_{i j}^{\kappa}$ denotes the mass of employed workers who are of skill type $i$ and origin $\kappa$ and are matched with a vacancy of skill type $j$. According to each of the above equations, a member of a sub-group can be in one of two states, either unemployed or matched with a vacancy of the same skill, with the exception of the high-skilled immigrants, who can also be mismatched.

Moreover, in steady state, where the flows in and out of unemployment for each skill sub-group are equal to each other, we have

$$
\begin{aligned}
u_{H}^{N} & =\lambda \frac{s_{H}}{s_{H}+m\left(\theta_{H}\right)}, \quad e_{H H}^{N}=\lambda \frac{m\left(\theta_{H}\right)}{s_{H}+m\left(\theta_{H}\right)}, \\
u_{L}^{N} & =(1-\lambda) \frac{s_{L}}{s_{L}+m\left(\theta_{L}\right)}, \quad e_{L L}^{N}=(1-\lambda) \frac{m\left(\theta_{L}\right)}{s_{L}+m\left(\theta_{L}\right)}, \\
u_{L}^{I} & =I_{L} \frac{s_{L}}{s_{L}+m\left(\theta_{L}\right)}, \quad e_{L L}^{I}=I_{L} \frac{m\left(\theta_{L}\right)}{s_{L}+m\left(\theta_{L}\right)}, \\
u_{H}^{I} & =I_{H} \frac{s_{H}\left[s_{L}+\gamma m\left(\theta_{H}\right)\right]}{\left[s_{H}+\gamma m\left(\theta_{H}\right)\right]\left[s_{L}+m\left(\theta_{L}\right)+\gamma m\left(\theta_{H}\right)\right]}, \quad e_{H H}^{I}=I_{H} \frac{\gamma m\left(\theta_{H}\right)}{s_{H}+\gamma m\left(\theta_{H}\right)}, \\
e_{H L}^{I} & =I_{H} \frac{s_{H} m\left(\theta_{L}\right)}{\left[s_{H}+\gamma m\left(\theta_{H}\right)\right]\left[s_{L}+m\left(\theta_{L}\right)+\gamma m\left(\theta_{H}\right)\right]} .
\end{aligned}
$$

Note that $e_{H L}^{I} /\left(e_{H L}^{I}+e_{H H}^{I}\right)$ is a measure of the overeducation ratio or the mismatch ratio among skilled immigrants. ${ }^{10}$

\footnotetext{
${ }^{10}$ In our model, the overeducation ratio and the mismatch ratio coincide.
} 
Next, using the above equations, we can rewrite the expressions regarding the probability that a firm finds a worker of a particular type (equations 5) as

$$
\phi_{H H}^{N}=\frac{\lambda}{\lambda+I_{H} \Omega_{H}}, \quad \phi_{L L}^{N}=\frac{1-\lambda}{1-\lambda+I_{L}+I_{H} \Omega_{L}}, \quad \phi_{L L}^{I}=\frac{I_{L}}{1-\lambda+I_{L}+I_{H} \Omega_{L}},
$$

where the expression for $\Omega_{H}$ is given by

$$
\Omega_{H}=\frac{\left(u_{H}^{I}+e_{H L}^{I}\right) / I_{H}}{u_{H}^{N} / \lambda}=\frac{s_{H}+m\left(\theta_{H}\right)}{s_{H}+\gamma m\left(\theta_{H}\right)} \geq 1 .
$$

The term $\Omega_{H}$ is greater than unity because the fraction of the native skilled workers who seek employment in the skilled sector is lower than that of the skilled immigrants, since the former find jobs at a higher rate than the latter $\left(m\left(\theta_{H}\right) \geq \gamma m\left(\theta_{H}\right)\right)$. Similarly,

$$
\Omega_{L}=\frac{u_{H}^{I} / I_{H}}{u_{L}^{I} / I_{L}}=\frac{u_{H}^{I} / I_{H}}{u_{L}^{N} / 1-\lambda}=\frac{s_{H}\left[s_{L}+\gamma m\left(\theta_{H}\right)\right]\left[s_{L}+m\left(\theta_{L}\right)\right]}{s_{L}\left[s_{H}+\gamma m\left(\theta_{H}\right)\right]\left[s_{L}+m\left(\theta_{L}\right)+\gamma m\left(\theta_{H}\right)\right]} .
$$

Notice that if $s_{H}=s_{L}=s$, then

$$
\Omega_{L}=\frac{s+m\left(\theta_{L}\right)}{s+m\left(\theta_{L}\right)+\gamma m\left(\theta_{H}\right)}<1
$$

i.e., the fraction of skilled immigrants who seek employment is lower than that of the unskilled immigrants (or natives), since the former find jobs at a higher rate $\left(m\left(\theta_{L}\right)+\right.$ $\left.\gamma m\left(\theta_{H}\right)>m\left(\theta_{L}\right)\right)$ and both groups lose jobs at the same rate $(s)$.

\section{Steady-State Equilibrium Analysis}

Definition. A steady-state equilibrium is a set $\left\{\theta_{j}^{*}, e_{i j}^{\kappa *}, u_{i}^{\kappa *}, w_{i j}^{\kappa *}\right\}$, where $i, j \in\{H, L\}$ and $\kappa \in\{N, I\}$, such that: $a$ ) the free-entry condition (11) for vacancies of each skill type $j$ is satisfied, $b$ ) the Nash bargaining optimality condition (12) for each skill type $i$ and origin $j$ holds, and $c$ ) the numbers of employed and unemployed workers for each skill type $i$ and origin $j$ remain constant and are given by equations (17).

Using equations (3), (4) and the free-entry conditions (equation 11), we derive the following system

$$
\begin{aligned}
\frac{c_{H}}{q\left(\theta_{H}\right)}= & \frac{1-\beta}{\lambda+I_{H} \Omega_{H}}\left\{\frac{\lambda\left(y_{H}-b_{H}\right)}{\Psi\left(\theta_{H}\right)}\right. \\
& \left.+\frac{\gamma I_{H} \Omega_{H}}{r+s_{H}+\beta \gamma m\left(\theta_{H}\right)}\left[y_{H}-b_{H}+h^{I}-\frac{\beta m\left(\theta_{L}\right)\left\{\mu y_{L}-\left[b_{H}-(1-\eta) h^{I}\right]\right\}}{\Psi\left(\theta_{L}\right)+\gamma m\left(\theta_{H}\right)}\right]\right\}
\end{aligned}
$$


$\frac{c_{L}}{q\left(\theta_{L}\right)}=\frac{1-\beta}{1-\lambda+I_{L}+I_{H} \Omega}\left\{\frac{\left(1-\lambda+I_{L}\right)\left(y_{L}-b_{L}\right)+I_{L} h^{I}}{\Psi\left(\theta_{L}\right)}+\frac{I_{H} \Omega_{L}\left\{\mu y_{L}-\left[b_{H}-(1-\eta) h^{I}\right]\right\}}{\Psi\left(\theta_{L}\right)+\gamma m\left(\theta_{H}\right)}\right\}$

The system of equations (19) and (20) describes the behavior of the two variables that measure the tightness in each market: $\theta_{H}$ and $\theta_{L}$. Having determined $\theta_{H}^{*}$ and $\theta_{L}^{*}$, we can obtain the equilibrium values of all other endogenous variables by substituting in the appropriate equations.

We are primarily interested in an equilibrium with the following features: $a$ ) both skilled and unskilled natives and immigrants are employed, $b$ ) there is cross-skill matching in which high-skilled immigrants work in both types of jobs and $c$ ) high-skilled immigrants conduct on-the-job search while employed in low-skill jobs. As shown in Appendix A.1.1, for such an equilibrium to exist the following restrictions on the parameter values must hold: $y_{i}>b_{i}, i=H, L, \mu y_{L}>b_{H}-(1-\eta) h^{I}$ and

$$
y_{H}>b_{H}-h^{I}+\frac{r+s_{H}+\beta \gamma m\left(\theta_{H}\right)+\beta m\left(\theta_{L}\right)}{\Psi\left(\theta_{L}\right)+\gamma m\left(\theta_{H}\right)}\left\{\mu y_{L}-\left[b_{H}-(1-\eta) h^{I}\right]\right\},
$$

(Condition for OTJ search)

where the last condition is necessary for the existence of on-the-job (OTJ) search; it implies that the surplus generated by a skilled immigrant and a skilled job is higher than that generated by a skilled immigrant and an unskilled job. Moreover, as shown in Appendix A.1.1, the Condition for OTJ search is sufficient for the employability of highskilled immigrants (EHSI) in high-skill jobs (see the Condition for EHSI in Appendix A.1.1). Notice that the Condition for OTJ search holds if, for example, $y_{H}>\mu y_{L}-\eta h^{I}$ and $s_{H}=s_{L}$, since, in this case, skilled immigrants in high-skill jobs receive a higher wage than mismatched immigrants and face the same probability of layoff when matched with a skilled vacancy (it may be recalled that $\Psi\left(\theta_{L}\right) \equiv r+s_{L}+\beta m\left(\theta_{L}\right)$ ). Hence, it pays for them to look for a high-skill job.

Finally, in the text below, we also analyze the case where $\mu y_{L}=b_{H}-(1-\eta) h^{I}$, as a benchmark case in which there is no cross-skill matching in equilibrium and hence there are no over-qualified immigrant workers, i.e., as shown in the Appendix A.1.1, when $\mu y_{L}=b_{H}-(1-\eta) h^{I}$, in equilibrium $\Pi_{H L}^{I}=0$ and $E_{H L}^{I}=U_{H}^{I}$ and thus $e_{H L}^{I}=0$. In other words, for this parameter configuration, there exists an equilibrium with ex post segmentation (Albrecht and Vroman, 2002; Dolado et al., 2009). In this equilibrium, high-skilled immigrants only take high-skill jobs. 
Proposition 1. Under certain parameter restrictions, a steady-state equilibrium exists and is unique.

Proof: All proofs are presented in Appendix A.1.

Consider next the effects of $\theta_{H}$ and $\theta_{L}$ on wages and (un)employment rates.

Proposition 2. Effects on wages and employment:

$$
\begin{aligned}
& \text { a) } \frac{d w_{H H}^{N}}{d \theta_{H}}>0, \quad \frac{d w_{H L}^{I}}{d \theta_{H}}<0, \quad \frac{d w_{H H}^{I}}{d \theta_{H}} \gtrless 0, \quad \frac{d w_{L L}^{N}}{d \theta_{L}}>0, \quad \frac{d w_{L L}^{I}}{d \theta_{L}}>0, \quad \frac{d w_{H L}^{I}}{d \theta_{L}}>0, \\
& \frac{d w_{H H}^{I}}{d \theta_{L}}>0 . \\
& \text { b) } \frac{d u_{i}^{N}}{d \theta_{i}}<0 \text { and } \frac{d e_{i j}^{N}}{d \theta_{i}}>0, i=j=H, L, \frac{d u_{L}^{I}}{d \theta_{L}}<0 \text { and } \frac{d e_{L L}^{I}}{d \theta_{L}}>0, \frac{d e_{H H}^{I}}{d \theta_{H}}>0 \\
& \frac{d e_{H L}^{I}}{d \theta_{L}}>0, \frac{d u_{H}^{I}}{d \theta_{L}}<0, \frac{d e_{H L}^{I}}{d \theta_{H}}<0 \text {, and } \frac{d u_{H}^{I}}{d \theta_{H}}<0 \text { if } s_{H}<s_{L} .
\end{aligned}
$$

All other cross-market effects are zero.

An increase in $\theta_{H}$ increases the probability that skilled native workers find a job and hence raises their bargaining position and their wages $\left(w_{H H}^{N}\right)$. It also increases the separation rate between a skilled immigrant and a low skill position, thus reducing $w_{H L}^{I}$. Finally, on the one hand, it raises the matching probability of high-skilled immigrant workers, but, on the other hand, it lowers their outside option by reducing $w_{H L}^{I}$. Hence, it has an ambiguous effect on $w_{H H}^{I}$.

Next, consider an increase in $\theta_{L}$. Naturally, it has a positive effect on the wages of low-skilled natives and immigrants $\left(w_{L L}^{N}\right.$ and $\left.w_{L L}^{I}\right)$. It also increases the outside option of high-skilled immigrants and raises their wages $\left(w_{H L}^{I}\right.$ and $\left.w_{H H}^{I}\right)$.

An increase in the tightness in market $i$ raises the probability of finding a job for workers of the same type and hence it lowers their unemployment level (raises their employment level). The employment level of mismatched workers $\left(e_{H L}^{I}\right)$ and the unemployment level of high-skilled immigrants $\left(u_{H}^{I}\right)$, in particular, depend on both tightness measures $\theta_{H}$ and $\theta_{L}$. An increase in $\theta_{L}$ raises the job finding rate of mismatched workers and thus increases their employment level and decreases the unemployment of high-skilled immigrants. On the other hand, an increase in $\theta_{H}$ results in a higher separation rate for mismatched workers and raises the job-finding rate for high-skilled immigrants. Consequently, there is a negative effect on the employment level of mismatched workers $e_{H L}^{I}$ and an ambiguous 
effect on the unemployment level of high-skilled immigrants $u_{H}^{I}$ (since there is also a positive effect on the employment level of high-skilled immigrants in high skill jobs, $e_{H H}^{I}$ ). Under the mild condition that $s_{H}<s_{L}$, the effect on the unemployment level $u_{H}^{I}$ becomes negative. $^{11}$

\subsection{The Effects of Cross-Skill Matching}

Next, we compare two otherwise identical economies: one with and one without cross-skill matching. In the first there exists an equilibrium in which skilled immigrants accept both high- and low-skill jobs (a cross-skill matching equilibrium), while in the second there exists an equilibrium in which skilled immigrants refuse to take low-skill jobs (an ex post segmentation equilibrium). The two equilibria occur for different parameter configurations; in particular, as mentioned above the latter equilibrium emerges if $\mu y_{L} \leq b_{H}-(1-\eta) h^{I}$. The following proposition analyzes the effects of cross-skill matching, i.e., the presence of over-qualified immigrants, on native workers.

Proposition 3. a) The presence of over-qualified immigrants hurts the high-skilled native workers. b) If $\mu=1$ and $b_{H}-(1-\eta) h^{I}>b_{L}$, then it hurts the low-skilled native workers as well.

As we show in Appendix A.1.4, the presence of over-qualified immigrants results in a lower tightness in the high-skilled market $\theta_{H}$. This is so, because cross-skill matching raises the outside option of high-skilled immigrants, which raises their wage and discourages job entry. Recall, from Proposition 2 above, that lower $\theta_{H}$ decreases the bargaining position of high-skilled native workers, which lowers their wage $w_{H H}^{N}$. Moreover, the finding rate of high skill jobs for these workers goes down and thus their unemployment rate, $u_{H}^{N} / \lambda$, goes up. Hence, high-skilled native workers lose both in terms of wages and employment.

We note that a corresponding result for low-skilled native workers cannot in general be established. In other words, the effect of cross-skill matching on $\theta_{L}$ is in general ambiguous. This is so for the following reasons: $a$ ) high-skilled immigrants may have higher output (recall that $\mu \geq 1$ ); $b$ ) on the other hand, they have a higher outside option than low-skilled natives and immigrants (if $b_{H}-(1-\eta) h^{I}>b_{L}$ ) and $c$ ) they search on the job, which results in higher separation rate. Whereas the first reason encourages entry of low-skill jobs and tends to raise $\theta_{L}$, the last two discourage entry and lower $\theta_{L}$. When

\footnotetext{
${ }^{11}$ The condition $s_{H}<s_{L}$ is verified in the data (see our next section).
} 
$\mu=1$, the first reason is cancelled; hence, only the last two reasons are valid and these lead to lower tightness in the low-skill labor market. It follows then that the presence of over-qualified immigrants leads to a lower $\theta_{L}$ and, from Proposition 2, this hurts the low-skilled native workers both in terms of employment and wages. Note, however, that if $\mu>1$ or $b_{H}-(1-\eta) h^{I}<b_{L}$, then the presence of overqualified immigrants has an ambiguous effect on low-skilled native workers.

\subsection{The Effects of Immigration}

In Proposition 3, we kept the number of immigrants constant and compared the labor market outcomes in two economies: one in which there is and one in which there is no cross-kill matching. In the following proposition, we analyze the effects on native workers of a change in the number of skilled and unskilled immigrants when there is cross-skill matching.

Proposition 4. Under conditions that ensure the existence and the uniqueness of a steady state: $a$ ) If $\mu=1$, then an increase in unskilled immigration $\left(I_{L}\right)$ benefits the unskilled native workers both in terms of employment and wages and hurts the skilled ones, $b)$ If $\mu=1, \gamma=1$ and $h^{I}$ is high enough $\left(h^{I}>\beta m_{L}\left(y_{L}-b_{H}\right) /\left(\Psi_{L}+m_{H}\right)\right)$, then an increase in skilled immigration $\left(I_{H}\right)$ benefits the skilled natives both in terms of employment and wages, but still has an ambiguous effect on the unskilled ones.

The low-skilled immigrants have the same productivity as low-skilled natives and mismatched immigrants (if $\mu=1$ ). At the same time, they receive a lower wage than unskilled natives because they have a lower outside option. ${ }^{12}$ Thus, an increase in their number raises the probability that a low-skill job finds a low-skilled immigrant, with a concomitant increase in the expected profit from the creation of a low-skill position. This spurs low-skill job entry, which raises the market tightness measure $\theta_{L}$, the low-skill native wage $w_{L L}^{N}$ and the low-skill employment level $e_{L L}^{N}$ in tandem. Since there are now more low-skill vacancies, it is easier for high-skilled immigrants to find employment in the low-skill market. Thus, they can bargain for a higher wage in the high-skill market, which decreases the profits of posing high-skill vacancies. Hence, firms post less high-skill vacancies than before and this leads to a lower wage and a lower employment level for high-skilled native workers. This cross-market effect would be absent in a similar model

\footnotetext{
${ }^{12}$ As explained above, they may even receive a lower wage than the mismatched immigrants.
} 
without cross-skill matching.

If the search cost of high-skilled immigrants exceeds the increase in their outside option because of the possibility of cross-skill matching and $\gamma=1$, then skilled immigrants receive a lower wage than skilled natives (see equations 13 and 16 , where if $\mu=\gamma=1$ and $h^{I}>$ $\beta m_{L}\left(y_{L}-b_{H}\right) /\left(\Psi_{L}+m_{H}\right)$, then $\left.w_{H H}^{I}<w_{H H}^{N}\right)$. Thus, an increase in skilled immigration raises the probability that a high-skill firm matches with a high-skilled immigrant and hence the expected profit from such a match. As a consequence, more high-skill jobs open and this increases the tightness measure $\theta_{H}$, the wage $w_{H H}^{N}$ and the employment level $e_{H H}^{N}$. Even in this simplified case, however, the effect of high-skill immigration on low-skilled natives is ambiguous. The increase in $\theta_{H}$ lowers the number of high-skilled immigrants who are unemployed (if $s_{H}<s_{L}$; see Proposition 2) and this tends to increase $\theta_{L}$. Nevertheless, the number of low-skill positions also decreases, since the separation rate between them and mismatched workers goes up. Thus, the overall effect on $\theta_{L}$ is ambiguous.

\subsection{The Effects of an Improvement in the Transferability of For- eign Human Capital}

In the third exercise, we consider an improvement in the transferability of human capital across borders, which in our model is captured by an increase in $\gamma$. In practice, there are several ways that this can be done. For example, one way to improve the transferability of human capital is to have foreign credentials assessed in the host country by independent organizations. To this end, several governments around the world have established foreign credential evaluation agencies. ${ }^{13}$ Another possible way is the establishment of transparent licensing requirements for all applicants, and especially foreign trained professionals. ${ }^{14}$ Moreover, bridging programs that enhance occupation-specific language proficiency and train with regard to licensing requirements and workplace norms in the host county can expedite the assimilation process for skilled immigrants. Finally, a better match in the

\footnotetext{
${ }^{13}$ For example, the Canadian government established in 2007 the Foreign Credentials Referral Office. In the US, whereas there is no such government agency, they are two private non-profit organizations that provide evaluations of foreign academic credential services, the Association of International Credential Evaluators and the National Association of Credential Evaluation Services, which have their own Codes of Conduct.

${ }^{14}$ For example, in 2006, the Ontario Legislature enacted the Fair Access to Regulated Professions Act to help immigrants qualify for thirty four provincially regulated professions. The Act requires professional associations to provide registration practices for foreign-trained professionals that are "transparent, objective, impartial and fair." Since then, other Canadian provinces have made similar commitments.
} 
labor market can occur through the selection of immigrants. For example, Australia is among the countries that have established a point system, which is intended as an objective method of selecting immigrant workers with the skills and attributes needed in the country. The success of such a system is reflected in the fact that Australian immigrants that were not selected based on skills (e.g., family-based immigrants) have the highest probability of being overeducated (see also Piracha and Vadean, 2013).

An increase in the transferability of human capital affects unskilled and skilled native workers via the tightness measures $\theta_{H}$ and $\theta_{L}$. In general, the effects are ambiguous because an increase in $\gamma$, one the one hand, raises the matching rate for high-skilled immigrants, but on the other, it also raises the separation rate between high-skilled immigrants and low-skill jobs. The first effect tends to raise the wage of mismatched workers while the second lowers it. As a result, there are countervailing effects applied on the tightness measures.

\section{Quantitative Analysis}

In this section, we calibrate the model to the US data and obtain quantitative results regarding the effects of $a$ ) cross-skill matching, $b$ ) immigration, and $c$ ) an improvement in the transferability of human capital. We use the parameter values to match the U.S. data for the period 1990-1999. We then simulate the effects of the increase in immigration that took place over the decade 2000-2009.

We are primarily interested in the effects on the wages and unemployment rates of skilled and unskilled native workers. Nevertheless, following, among others, Acemoglu (2001) and Chassamboulli and Palivos (2013, 2014), we also calculate the impact of immigration on the total steady-state surplus of the economy, i.e., the total income accrued to natives net of the flow cost of vacancies. We make the assumption that all firms belong to natives, who receive all the profits. Thus, our measure of net income to natives (labelled surplus1) is

$$
\begin{aligned}
\text { surplus1 }= & \left(e_{H H}^{N}+e_{H H}^{I}\right) y_{H}+\left(e_{L L}^{N}+e_{L L}^{I}\right) y_{L}+e_{H L}^{I} \mu y_{L}+u_{H}^{N} b_{H}+u_{L}^{N} b_{L} \\
& -v_{H} c_{H}-v_{L} c_{L}-e_{H H}^{I} w_{H H}^{I}-e_{L L}^{I} w_{L L}^{I}-e_{H L}^{I} w_{H L}^{I} .
\end{aligned}
$$

We also compute an alternative measure of income, labelled surplus2, which does not 
include the income of the unemployed, that is,

$$
\text { surplus2 }=\text { surplus1 }-u_{H}^{N} b_{H}-u_{L}^{N} b_{L}
$$

\subsection{Calibration}

One period in the model represents one month, so all the parameters are interpreted monthly. Also, we define as "immigrants" non-citizens and naturalized citizens. Finally, a skilled worker is one with at least a Bachelor's degree.

Based on the seminal work of Blanchard and Diamond (1991), we use Cobb-Douglas matching functions in each of the two labor markets; more specifically, the matching functions are $M_{H}=A_{H}\left(u_{H}^{N}+u_{H}^{I}+e_{H L}^{I}\right)^{\alpha} v_{H}^{1-\alpha}$ in the skilled market and $M_{L}=A_{L}\left(u_{L}^{N}+\right.$ $\left.u_{L}^{I}+u_{H}^{I}\right)^{\alpha} v_{L}^{1-\alpha}$ in the unskilled market, where the scale parameters $A_{i}, i=H, L$, index the efficiency of each of the two matching processes.

There are 20 parameters needed to be determined: the monthly interest rate $r$, the unemployment elasticity of the matching function $\alpha$, the matching efficiency parameters $A_{H}$ and $A_{L}$, the workers' bargaining power $\beta$, the share of native skilled labor force $\lambda$, the numbers of skilled and unskilled immigrants $I_{H}$ and $I_{L}$, the monthly separation rates $s_{H}$ and $s_{L}$, the vacancy $\operatorname{costs} c_{H}$ and $c_{L}$, the search cost parameters $\eta$ and $h^{I}$, the productivity parameters $y_{L}, y_{H}$ and $\mu$, the unemployment flow incomes $b_{H}$ and $b_{L}$, and the parameter $\gamma$ that captures the transferability of human capital across borders.

First, for the monthly interest rate we use the commonly-used value of 0.004 . This is the monthly rate that corresponds to an annual real interest rate of $4.76 \%$, calculated as the difference between the 30-year treasury constant maturity bond rate and the average GDP deflator over the period 1990-1999 (the data are from the Federal Reserve Bank of Saint Louis). Second, following the literature we set the unemployment elasticity of the matching function $(\alpha)$ and the workers' bargaining power parameter $(\beta)$ equal to 0.5. Third, following the estimates of Chassamboulli and Palivos (2014) for the U.S. economy, the percentage of US-born workers with a Bachelor's degree $(\lambda)$ is set to 0.274 , the monthly skilled and unskilled separation rates are $s_{H}=0.019$ and $s_{L}=0.034$, and the normalized numbers, i.e., the raw numbers divided by the native labor force, of skilled and unskilled immigrants are set to $I_{H}=0.036$ and $I_{L}=0.089$. Fourth, the productivity of unskilled workers $\left(y_{L}\right)$ is normalized to 1 . Fifth, in the main text, we use the value of $\mu=1.00$ for the relative productivity of high-skilled workers in low-skill jobs, i.e., high-skilled and 
Table 1: Baseline Parameter Values

\begin{tabular}{ll}
\hline Value & Interpretation \\
\hline \hline$r=0.004$ & Monthly real interest rate. \\
$\alpha=0.5$ & Unemployment elasticity of the matching function. \\
$\beta=0.5$ & Workers' bargaining power. \\
$\lambda=0.274$ & Share of native skilled labor force. \\
$I_{H}=0.036, I_{L}=0.089$ & Normalized number of skilled and unskilled immigrants. \\
$s_{H}=0.019, s_{L}=0.034$ & Monthly skilled and unskilled separation rates. \\
$y_{L}=1$ & Normalized productivity of low-skilled workers. \\
$\eta=0.5$ & Relative search cost of mismatched workers \\
$\mu=1.00$ & Relative productivity of high-skilled workers in low-skill jobs \\
\hline
\end{tabular}

low-skilled workers are equally productive in low-skill jobs. Nevertheless, we provide a sensitivity analysis with respect to this parameter, which is presented in Appendix A.2.1. Finally, we assume that $\eta=0.5$, but we have also conducted sensitivity analysis with respect to this parameter as well (see Appendix A.2.3). Table 1 summarizes these 11 parameter values.

The remaining 9 parameters are jointly calibrated to match the following 9 calibration targets obtained from the U.S. data over the period of interest: ${ }^{15} a$ ) the average employment rates of workers with at least a Bachelor's degree and of workers with less than a Bachelor's degree are 0.976 and 0.939 , respectively; $b$ ) the college-plus wage premium is $61.1 \% ; c$ ) the native-immigrant wage gap is $0.19 ; d$ ) the vacancy to unemployment ratios are equal to $0.620 ; e$ ) the replacement ratios (ratio of unemployment to employment income) are set to 0.50 , a value that is between Hall and Milgrom's estimate of 0.71 (Hall and Milgrom, 2008) and Shimer's estimate of 0.40 (Shimer 2005) (we have also computed the results using the alternative value of 0.71 in Appendix A.2.2); and $f$ ) the overeducation ratio for high-skilled immigrants is $0.2{ }^{16}$ The calibrated parameter values are presented in Table 2 .

\footnotetext{
${ }^{15}$ We borrow the targets a)-d) from Chassamboulli and Palivos (2014), where one can find detailed explanations on how they are computed.

${ }^{16}$ Beckhusen et al. (2013) estimate that the overeducation ratio exceeds 40 percent for immigrants with a bachelor's degree, 50 percent for those with a doctoral/professional degree, and 75 percent for those with a master's degree. For comparable natives, the overeducation ratio is between 10 to 20 percentage points lower. Given that, in our model, natives are not overeducated, we set the overeducation ratio for immigrants to 20 percent.
} 
Table 2: Values of the Calibrated Parameters

\begin{tabular}{ll}
\hline Value & Interpretation \\
\hline \hline$c_{L}=1.189, c_{H}=3.590$ & Vacancy costs \\
$A_{L}=0.665, A_{H}=1.463$ & Matching efficiency parameters \\
$h^{I}=2.878$ & Search cost \\
$y_{H}=1.579$ & Relative productivity of high-skilled workers \\
$b_{L}=0.484, b_{H}=0.779$ & Unemployment flow incomes \\
$\gamma=0.077$ & Transferability of foreign human capital \\
\hline
\end{tabular}

\subsection{Results}

As in Section 3, we perform three basic exercises; specifically, we analyze the effects on native workers of: a) cross-skill matching (we examined this theoretically in Proposition $3), b$ ) an increase in immigration (see Proposition 4), and c) an improvement in the transferability of foreign human capital (see subsection 3.3). In these exercises, the restrictions on the parameters mentioned above and in Appendix A.1.1 hold, except, of course for the case where we change the parameter values to obtain the ex post segmentation (no cross-skill matching) equilibrium.

\subsubsection{Cross-skill matching}

In Table 3, we present the results from going from the ex post segmentation equilibrium (no cross-skill matching) to the cross-skill matching equilibrium. In the latter equilibrium, skilled immigrants accept both skilled and unskilled jobs. To obtain the case where there is no cross-skill matching, we change the parameters $\mu$ and $\eta$ so that $\mu y_{L}=b_{H}-(1-\eta) h^{I}$ and in equilibrium skilled immigrants refuse to take low-skill jobs. All the parameters that concern the native workers remain the same; changes that affect them occur only through the tightness measures $\theta_{L}$ and $\theta_{H}$. In agreement with Proposition $3 \mathrm{a}$, high-skill workers lose from cross-skill matching, both in terms of employment and wages. Whereas the effect on wages is rather small, there is a sizeable impact on unemployment. This is so, because cross-skill matching raises the outside option of high-skilled immigrants, which increases their wage and discourages job entry. However, low-skilled native workers experience a small gain from cross-skill matching. This occurs because according to our parameterization high-skilled immigrants have a lower outside option than low-skilled natives $\left(b_{H}-(1-\eta) h^{I}<b_{L}\right)$, and hence the tightness in the low-skill market $\theta_{L}$ goes up. The search cost while unemployed is so high for skilled immigrants that they prefer to get an unskilled job even at a very low wage and continue to search in the high-skill sector. 
Table 3 presents also the effects on immigrants. As expected, low-skilled immigrants gain because of the increase in the tightness $\theta_{L}$, whereas high-skilled workers gain because cross-skill matching gives them more options.

Table 3: The Effects of Cross-skill Matching

\begin{tabular}{|c|c|}
\hline \multicolumn{2}{|c|}{ From No Cross-skill Matching to Cross-skill Matching } \\
\hline Value & \% Change \\
\hline \multicolumn{2}{|c|}{ Unskilled Natives } \\
\hline Wage $\left(w_{L L}^{N}\right)$ & 0.03 \\
\hline Unemployment Rate $\left(\frac{u_{L}^{N}}{1-\lambda}\right)$ & -0.82 \\
\hline Labor Market Tightness $\left(\theta_{L}\right)$ & 1.76 \\
\hline \multicolumn{2}{|c|}{$\begin{array}{l}\text { Skilled Natives } \\
\end{array}$} \\
\hline Wage $\left(w_{H H}^{N}\right)$ & -0.21 \\
\hline Unemployment Rate $\left(\frac{u_{H}^{N}}{\lambda}\right)$ & 19.52 \\
\hline Labor Market Tightness $\left(\theta_{H}\right)$ & -30.52 \\
\hline \multicolumn{2}{|c|}{$\begin{array}{ll}\text { Overall Natives } \\
\end{array}$} \\
\hline Wage & -0.11 \\
\hline Unemployment Rate & 3.79 \\
\hline Surplus1 & -0.04 \\
\hline Surplus2 & -0.09 \\
\hline \multicolumn{2}{|c|}{ Unskilled Immigrants } \\
\hline Wage $\left(w_{L L}^{I}\right)$ & 0.21 \\
\hline Unemployment Rate $\left(\frac{u_{L}^{I}}{I_{L}}\right)$ & -0.82 \\
\hline \multicolumn{2}{|c|}{$\begin{array}{l}\text { Skilled Immigrants } \\
\end{array}$} \\
\hline Wage $\left(w_{H H}^{I}\right)$ & 19.05 \\
\hline Employment Rate $\left(\frac{e_{H H}^{I}}{I_{H}}\right)$ & -3.81 \\
\hline \multicolumn{2}{|c|}{$\begin{array}{ll}\text { Overall Skilled Immigrants } \\
\end{array}$} \\
\hline Wage & 12.47 \\
\hline Unemployment Rate & -81.80 \\
\hline \multicolumn{2}{|c|}{$\begin{array}{lc}\text { Overall Immigrants } \\
\end{array}$} \\
\hline Wage & 4.65 \\
\hline Unemployment Rate & -51.13 \\
\hline
\end{tabular}

Finally, Table A.7 in Appendix A.2.2 presents the results for the case where the replacement ratio is 0.71 , as estimated in Hall and Milgrom (2008). As can be seen, the differences are qualitatively in the same direction and quantitatively small.

\subsubsection{An increase in immigration}

We analyze the effects of the low-skill and high-skill immigration influx that took place in the U.S. during the decade 2000-2009. The normalized changes in $I_{L}$ and $I_{H}$ over the period 2000-2009, calculated using the Public Use Microdata Sample (PUMS) of the 1990 and 2000 US Census, are 0.051 and 0.026 , respectively, that is, 5.1 and 2.6 percent of the 
native labor force. ${ }^{17}$

In Table 4, we summarize the effects of immigration on the native skilled and unskilled workers. More specifically, we consider first a change in unskilled immigration only, which is of the same magnitude as the one found in the data, i.e., $\Delta I_{L}=0.051$ (second column in Table 4). Next, we consider a change in skilled immigration equal to $\Delta I_{H}=0.026$ (third column) and finally we analyze the effects of an immigration influx that is of the same magnitude and composition as the one in the data, i.e., $\Delta I_{L}=0.051$ and $\Delta I_{H}=0.026$.

\begin{tabular}{|c|c|c|c|}
\hline \multicolumn{4}{|c|}{ (Percentage Changes) } \\
\hline Variable & $I_{L}$ & $I_{H}$ & $I_{L}$ and $I_{H}$ \\
\hline \multicolumn{4}{|c|}{ Unskilled Natives } \\
\hline Wage $\left(w_{L L}^{N}\right)$ & 0.24 & 0.02 & 0.25 \\
\hline Unemployment Rate $\left(\frac{u_{L}^{N}}{1-\lambda}\right)$ & -7.74 & -0.52 & -8.03 \\
\hline Labor Market Tightness $\left(\theta_{L}\right)$ & 18.65 & 1.12 & 19.45 \\
\hline \multicolumn{4}{|c|}{ Skilled Natives } \\
\hline Wage $\left(w_{H H}^{N}\right)$ & -0.01 & 0.06 & 0.05 \\
\hline Unemployment Rate $\left(\frac{u_{H}^{N}}{\lambda}\right)$ & 0.50 & -4.37 & -3.82 \\
\hline Labor Market Tightness $\left(\theta_{H}\right)$ & -1.02 & 9.57 & 8.30 \\
\hline \multicolumn{4}{|c|}{ Overall Natives } \\
\hline Wage & 0.09 & 0.04 & 0.13 \\
\hline Unemployment Rate & -5.52 & -1.55 & -6.90 \\
\hline Surplus1 & 0.96 & 0.33 & 1.26 \\
\hline Surplus2 & 1.13 & 0.37 & 1.47 \\
\hline \multicolumn{4}{|c|}{ Unskilled Immigrants } \\
\hline Wage $\left(w_{L L}^{I}\right)$ & 1.98 & 0.13 & 2.06 \\
\hline Unemployment Rate $\left(\frac{u_{L}^{I}}{I_{L}}\right)$ & -7.74 & -0.52 & -8.03 \\
\hline \multicolumn{4}{|c|}{ Skilled Immigrants } \\
\hline Wage $\left(w_{H H}^{I}\right)$ & 0.43 & 1.15 & 1.54 \\
\hline Employment Rate $\left(\frac{e_{H H}^{I}}{I_{H}}\right)$ & -0.12 & 1.03 & 0.90 \\
\hline Wage $\left(w_{H L}^{I}\right)$ & 1.90 & -0.51 & 1.37 \\
\hline Over-Education Ratio & 1.50 & -3.91 & -2.40 \\
\hline \multicolumn{4}{|c|}{ Overall Skilled Immigrants } \\
\hline Wage & 0.57 & 1.13 & 1.65 \\
\hline Unemployment Rate $\left(\frac{u_{H}^{I}}{I_{H}}\right)$ & -6.89 & -1.47 & -8.05 \\
\hline \multicolumn{4}{|c|}{$\begin{array}{l}\text { Overall Immigrants } \\
\end{array}$} \\
\hline Wage & -0.58 & 3.79 & 2.40 \\
\hline Unemployment Rate & -0.74 & -10.60 & -8.53 \\
\hline
\end{tabular}

As seen in Table 4, an increase in unskilled immigration raises the wage of low-skilled native workers and lowers their unemployment rate, while it has the opposite effects on high-skilled native workers. As explained in Proposition 4, this occurs because an increase

\footnotetext{
${ }^{17}$ Notice that $I_{H} /\left(I_{L}+I_{H}\right)=0.338>\lambda=0.274$, i.e., the new immigration flow was college intensive. In fact, this pattern appears in virtually all OECD countries (see Docquier, Ozden and Peri, 2014).
} 
in the number of unskilled immigrants reduces the labor cost that a low-skill firm expects to pay. On the other hand, it raises the outside option of mismatched workers (it is easier for them to find a low-skill job) and hence it increases the labor cost that a high-skill firm expects to pay. Consequently, the increase in unskilled immigration induces entry in the low-skill and exit in the high-skill sector. Put differently, the market tightness goes up in the first and down in the second sector. Note that these results are opposite from what one obtains in a competitive model, which is to see factors that are similar to unskilled immigration to lose and factors that are different to gain. The underlying sources of those effects are a constant returns to scale production function and a competitive labor market, which imply diminishing marginal products - as the number of unskilled workers increases, their marginal product and hence their wage decreases- and factor complementarity -as the number of unskilled workers increases, the marginal product and hence the wage of skilled workers increases. On the contrary, in the present model, it is the higher search cost of the low-skilled immigrants that drives the gain of unskilled natives and the possibility of cross-skill matching that leads to the loss of high-skilled natives. In Proposition 4, we showed even analytically these results for the case where $\mu=1$. Nevertheless, our simulation exercise confirms that this is the case even for higher values of $\mu$ (Tables A.1 and A.4 in Appendix A.2.1 present the results for the case where $\mu=1.2$; in Table A.1 we change the value of $\mu$, but keep all other parameter values the same, while in Table A.4 we set the value of the relative productivity parameter $\mu=1.2$ and then recalibrate the model to match all targets). ${ }^{18}$

Consider next an increase in the number of skilled immigrants. As shown in Proposition 4, this leads to an increase in the wage and a decrease in the unemployment rate of high-skilled native workers. This is so because the induced entry increases the number of jobs per worker $\theta_{H}$. On the other hand, the effect on $\theta_{L}$ is in general ambiguous, since the increase in $\theta_{H}$ has two conflicting effects: first, it decreases the number of unemployed high skilled immigrants and tends to raise $\theta_{L}$ and second, it raises the separation rate between low-skill jobs and skilled immigrants, which induces firm exit and leads to a lower $\theta_{L}$. Nevertheless, as shown in Table 4 (third column), the first effect dominates and the overall result is positive (although small) on low-skilled workers. Furthermore, these results are robust to alternative values of $\mu$ (as above, Tables A.1 and A.4 in Appendix

\footnotetext{
${ }^{18}$ Although we have experimented with different values of $\mu$, we have always maintain the (reasonable) restriction that $\mu y_{L}<y_{H}$. For higher values of $\mu$, skilled immigrants may not be willing to work in the skilled sector.
} 
A.2.1 present the results for the cases where $\mu=1.20)$.

Finally, the last column in Table 4 presents the case where both skilled and unskilled immigration take place at the same time. The net result is an increase in the wages of both skilled and unskilled natives and a decrease in their unemployment rates. In the Appendix, we also examine the sensitivity of the results with respect to the replacement ratio (in Table A.8 in Appendix A.2.2 we raise the replacement ratio to 0.71) as well as with respect to the relative search cost parameter for mismatched workers $\eta$ (Table A.10 in Appendix A.2.3 presents the case where we change the value of $\eta$ from 0.5 to 0.75 , but keep all other parameter values the same, while Table A.13 presents the case where we set the value of $\eta=0.75$ and then recalibrate the model to match all targets). In general, the differences between these Tables are qualitatively in the same direction and quantitatively small. There is only one small difference. The impact of skilled immigration is positive on low-skilled native workers in Table 4 and negative in Tables A.10 and A.13. This is so because the higher search cost results in a lower wage rate $w_{H H}^{I}$ for high skilled immigrants (their outside option is lower and their bargaining position weakens). This means that, following an increase in skilled immigration, the matching rate in the high-skill sector and hence the separation rate between low-skill firms and high-skilled immigrants is higher; hence, there is exit in the low-skill sector, a drop in $\theta_{L}$, with a concomitant decrease in $w_{L L}^{N}$ and an increase in $u_{L L}^{N}$.

\subsubsection{Transferability of Human Capital}

Our final exercise simulates the effects of an improvement in the transferability of human capital across borders. As mentioned above, this can be achieved through the establishment of programs that enhance occupation-specific language proficiency, training programs regarding licensing requirements and workplace norms and practices in the host county, foreign educational credentials and work experience evaluation agencies, etc.

Table 5 presents the results. In all cases, we consider a change in $\gamma$ starting from $\gamma=0.077$ (overeducation ratio for high-skilled immigrants 20\%). The new values of $\gamma$ that we consider are (overeducation ratios in parentheses): 0.06 (25.7\%), 0.10 (15.3\%), $0.20(7.1 \%)$ and $0.80(1.3 \%) .{ }^{19}$ As can be seen in Table 5, if, starting from an overeducation ratio of twenty percent, $\gamma$ increases (decreases) then the low-skilled native workers lose

\footnotetext{
${ }^{19}$ We present the results for values above and below the benchmark value of 0.077 to demonstrate the monotonicity of the effects.
} 
(gain) both in terms of wages and employment. This is so, because, for example, an increase in $\gamma$ raises the separation rate between high-skilled workers and low-skill jobs, which discourages entry in the low-skill sector $\left(\theta_{L}\right.$ decreases) and makes it more difficult for low-skilled workers to find employment. As a result, their wage goes down and their unemployment rate increases.

On the other hand, an increase in $\gamma$ initially raises the wage and employment of highskilled workers; an increase in $\gamma$ raises the probability that a match between a skilled immigrant and a skilled position will be consummated, which, given that under the particular parameterization $w_{H H}^{I}<w_{H H}^{N}$, induces entry in the high skill sector $\left(\theta_{H}\right.$ increases $)$ and improves the bargaining position of workers. ${ }^{20}$ Interestingly, however, after a point, as $\gamma$ increases and the wage rates of skilled natives and immigrants increase, the expected profit $\phi_{H H}^{N} \Pi_{H H}^{N}+\left(1-\phi_{H H}^{N}\right) \gamma \Pi_{H H}^{I}$ starts declining. In other words, the additional cost to the firm owing to the higher wages that it has to pay outweigh the benefit of the increase in $\gamma$. As a result, the initial flow direction reverses and there is now exit of high-skill positions $\left(\theta_{H}\right.$ decreases $)$. This lowers the wage of skilled workers and raises their unemployment rate (the maximum of the profit occurs around $\gamma=0.18$; on the other hand, starting from $\gamma=0.077$, any change that leads to a value of $\gamma>0.55$ will decrease $\left.\theta_{H}\right)$. In sum, the behavior of the employment and unemployment rates $\left(e_{H H}^{N} / \lambda\right.$ and $\left.u_{H}^{N} / \lambda\right)$, the tightness measure and the matching rate $\left(\theta_{H}\right.$ and $\left.m\left(\theta_{H}\right)\right)$ and the wage rate of high-skilled native workers $\left(w_{H H}^{N}\right)$ is not monotonic.

Table 5 presents also the overall results for natives (in terms of wages and unemployment) as well as the two measures of the surplus (surplus1 and surplus2, where it may be recalled that the second measure does not include the -imputed- unemployment income). The overall results are initially positive in terms of wages and employment, whereas the change in surplus1 (surplus2) is negative (positive). Thus, initially an improvement in the transferability of human capital benefits the high-skilled and hurts the low-skilled natives; moreover, the net effects are either positive or negative, depending on the measure of the surplus used. Nevertheless, at high values of $\gamma$ (small overeducation ratios), further improvements in the transferability make both types of native workers worse off in terms of wages and employment and decrease the net income of the economy.

The effects on immigrants are also presented in Table 5. The decline in the wage and

\footnotetext{
${ }^{20}$ Recall that in principle $w_{H H}^{I}$ could be higher or lower than $w_{H H}^{N}$. The parameter values that we use imply $w_{H H}^{I}<w_{H H}^{N}$.
} 
the employment rate of low-skilled immigrants follows directly from the change in the relevant matching rate $m\left(\theta_{L}\right)$. As regards the skilled immigrants, there are two effects on their matching rate $\gamma m\left(\theta_{H}\right)$ : one owing to the change in $\gamma$ and one owing to the change in $\theta_{H}$. For high values of the overeducation ratio (low values of $\gamma$ ), when an increase in $\gamma$ raises $\theta_{H}$, both effects are positive on the wage and the employment rate. On the other hand, for low values of the overeducation ratio (high values of $\gamma$ ), when an increase in $\gamma$ lowers $\theta_{H}$, the effect of the increase in $\gamma$ is positive, whereas the effect from the decrease in $\theta_{H}$ is negative. Nevertheless, the former effect dominates; that is why the wage rate $\left(w_{H H}^{I}\right)$ and the employment rate $\left(e_{H H}^{I} / I_{H}\right)$ for skilled immigrants continue to increase.

Table 5: The Effects of a Change in the Transferability of Human Capital (Percentage Changes)

\begin{tabular}{|c|c|c|c|c|}
\hline Variable & $\gamma=0.06$ & $\gamma=0.10$ & $\gamma=0.20$ & $\gamma=0.80$ \\
\hline Overeducation Ratio (\%) & 25.7 & 15.3 & 7.1 & 1.3 \\
\hline \multicolumn{5}{|c|}{ Unskilled Natives } \\
\hline Wage $\left(w_{L L}^{N}\right)$ & 0.00 & -0.01 & -0.02 & -0.03 \\
\hline Unemployment Rate $\left(\frac{u_{L}^{N}}{1-\lambda}\right)$ & -0.16 & 0.16 & 0.57 & 1.04 \\
\hline Labor Market Tightness $\left(\theta_{L}\right)$ & 0.34 & -0.34 & -1.20 & -2.17 \\
\hline \multicolumn{5}{|c|}{$\begin{array}{c}\text { Skilled Natives } \\
\end{array}$} \\
\hline Wage $\left(w_{H H}^{N}\right)$ & -0.06 & 0.04 & 0.08 & -0.05 \\
\hline Unemployment Rate $\left(\frac{u_{H}^{N}}{\lambda}\right)$ & 4.66 & -3.20 & -5.80 & 3.57 \\
\hline Labor Market Tightness $\left(\theta_{H}\right)$ & -8.91 & 6.89 & 13.01 & -6.93 \\
\hline \multicolumn{5}{|c|}{ Overall Natives } \\
\hline Wage & -0.03 & 0.02 & 0.04 & -0.04 \\
\hline Unemployment Rate & 1.14 & -0.74 & -1.14 & 1.72 \\
\hline Surplus1 & -0.00 & -0.02 & -0.12 & -0.38 \\
\hline Surplus2 & -0.02 & -0.01 & -0.11 & -0.42 \\
\hline \multicolumn{5}{|c|}{ Unskilled Immigrants } \\
\hline Wage $\left(w_{L L}^{I}\right)$ & 0.04 & -0.04 & -0.15 & -0.26 \\
\hline Unemployment Rate $\left(\frac{u_{L}^{I}}{I_{L}}\right)$ & -0.16 & 0.16 & 0.57 & 1.04 \\
\hline \multicolumn{5}{|c|}{ Skilled Immigrants } \\
\hline Wage $\left(w_{H H}^{I}\right)$ & -7.34 & 6.95 & 21.96 & 38.80 \\
\hline Employment Rate $\left(\frac{e_{H H}^{I}}{I_{H}}\right)$ & -7.39 & 6.15 & 17.06 & 25.94 \\
\hline Wage $\left(w_{H L}^{I}\right)$ & 3.74 & -4.42 & -18.51 & -47.93 \\
\hline Overeducation Ratio & 28.66 & -23.59 & -64.34 & -93.63 \\
\hline \multicolumn{5}{|c|}{ Overall Skilled Immigrants } \\
\hline Wage & -6.71 & 7.09 & 24.34 & 45.55 \\
\hline Unemployment Rate $\left(\frac{u_{H}^{I}}{I_{H}}\right)$ & 6.50 & -6.30 & -22.41 & -54.82 \\
\hline \multicolumn{5}{|c|}{ Overall Immigrants } \\
\hline Wage & -2.31 & 2.45 & 8.43 & 15.95 \\
\hline Unemployment Rate & 0.50 & -0.46 & -1.56 & -4.24 \\
\hline
\end{tabular}

Finally, Tables A.2 and A.5 in Appendix A.2.1 present the results of the exercise for a value of the relative productivity parameter equal to $\mu=1.2$, Table A.9 in Appendix 
A.2.2 for a replacement ratio 0f 0.71 and Tables A.11 and A.14 in Appendix A.2.3 for a value of the relative search cost parameter $\eta=0.75$. In all cases, the results are robust.

\section{Conclusions}

The overeducation of immigrants is a prominent feature in labor markets. In this paper, we investigate how this phenomenon affects the labor market outcomes in the host country. We do so for an economy in which frictions in the labor market generate unemployment and wages are not competitively determined but are instead the outcome of bilateral bargaining between workers and firms. There are also several other features in our model. First, there exists skill heterogeneity among native and immigrant workers, which allows for the study of the distributional effects across various groups of the labor force; namely, unskilled and skilled native workers experience different effects from immigration flows and related economic policies. Second, there is differential search cost between natives and immigrants, which generates an equilibrium wage gap between equally productive workers; that is, immigrants of a certain skill receive a lower wage than equally productive natives. This makes them more attractive to a firm. As a consequence, any immigration movement will affect the firms' incentives to create new vacancies. Third, there is imperfect transferability of human capital across borders, which puts skilled immigrants at a disadvantage relative to skilled natives. This and the possibility of cross-skill matching makes skilled immigrants willing to accept low-skill jobs, leading to overeducation and more generally qualification mismatches. Finally, there is on-the-job search on behalf of mismatched workers, which makes these skill mismatches transitory.

We calibrate the model to the US economy and assess quantitatively the impact of three changes. First, we analyze the effects of a movement from a segmentation equilibrium, where there is no cross-skill matching, to a cross-skill matching equilibrium. We find that cross-skill matching benefits the unskilled and hurts the skilled native workers. Similarly, new unskilled immigration benefits the low-skilled native workers and hurts the high-skilled. On the other hand, new skilled immigration benefits both skilled and unskilled natives. Moreover, when we simulate the effects of the actual US immigration influx that took place between the years 2000 and 2009, we find that both skilled and unskilled native workers gain. We also find that initially an improvement in the transferability of human capital benefits the high-skilled natives at the expense of the 
low-skilled. Nevertheless, below a certain overeducation ratio, further improvements in the transferability of human capital make both types of native workers worse off.

We believe that our framework can be extended in a number of different ways. For example, the percentage of skilled native workers is taken as given in our model. A natural extension would be to allow for endogenous skill acquisition on behalf of native workers and study how this decision is influenced by the presence of overeducated immigrants. The key determinant factor for the education decision is the future return to human capital. It would be interesting to study how this return responds to the immigration of new human capital or to policies that improve its transferability. 


\section{References}

[1] Acemoglu, D. (2001). "Good Jobs versus Bad Jobs," Journal of Labor Economics 19(1), pp. 1-21.

[2] Albrecht, J., and S. Vroman (2002). "A Matching Model with Endogenous Skill Requirements," International Economic Review 43(1), pp. 283-305.

[3] Aleksynska, M. and A. Tritah (2013). "Occupation-Education Mismatch of Immigrant Workers in Europe: Context and Policies," Economics of Education Review, 36(C), pp. 229-244.

[4] Baker, M., and D. Benjamin (1994). "The Performance of Immigrants in the Canadian Labour Market," Journal of Labor Economics 12(3), pp. 369-405.

[5] Battisti, M., G. Felbermayr, G. Peri, and P. Poutvaara (2014). "Immigration, Search, and Redistribution: A Quantitative Assessment of Native Welfare," NBER Working Paper No. 20131.

[6] Beckhusen, J., R. J. G. M. Florax, J. Poot and B. S. Waldorf (2013). "Attracting Global Talent and then What? Overeducation among Immigrants in the US," Journal of Regional Science 53(5), pp. 834-854.

[7] Belan, P., M. Carré and S. Gregoir (2010). "Subsidizing Low-Skilled Jobs in a Dual Labor Market," Labour Economics 17(5), pp. 776-788.

[8] Bell, B. (1997). "The Performance of Immigrants in the United Kingdom: Evidence from the GHS," Economic Journal 107(441), pp. 333-344.

[9] Blanchard, O., and P. Diamond (1991). "The Aggregate Matching Function," NBER Working Paper No. 3175.

[10] Chassamboulli, A. (2011). "Cyclical Upgrading of Labor and Employment Differences across Skill Groups," The B.E. Journal of Macroeconomics 11(1) (Contributions), Article 14 .

[11] Chassamboulli A., and T. Palivos (2013). "The Impact of Immigration on the Employment and Wages of Native Workers," Journal of Macroeconomics 38(Part A), pp. 19-34

[12] Chassamboulli, A., and T. Palivos (2014). "A Search-Equilibrium Approach to the Effects of Immigration on Labor Market Outcomes," International Economic Review 55(1), pp. 111-129.

[13] Chassamboulli, A., and G. Peri (2014). "The Labor Market Effects of Reducing Undocumented Immigrants," NBER Working Paper No. 19932.

[14] Chiswick, B. R. , (1978). "The Effect of Americanization on the Earnings of Foreignborn Men," Journal of Political Economy 86(5), pp. 897-921.

[15] Chiswick, B. R., and P. W. Miller (2009). "The International Transferability of Immigrants' Human Capital Skills," Economics of Education Review 28(2), pp. 152-169. 
[16] Chiswick, B. R. and P. W. Miller (2010). "The Effects of Educational Occupational Mismatch on Immigrant Earnings in Australia, with International Comparisons," International Migration Review 44(4), pp. 869-898

[17] Constant, A., and D. S. Massey (2003). "Self-Selection, Earnings, and Out-Migration: A Longitudinal Study of Immigrants to Germany," Journal of Population Economics 16(4), pp. 631-653.

[18] Docquier, F., Ç. Ozden, and G. Peri (2014). "The Labour Market Effects of Immigration and Emigration in OECD Countries." Economic Journal, forthcoming. doi: 10.1111/ecoj.12077.

[19] Dolado, J. J., M. Jansen and J. F. Jimeno (2009). "On-the-Job Search in a Matching Model with Heterogeneous Jobs and Workers," Economic Journal 119(534), pp. 200228.

[20] Freeman, R. (1976). The Overeducated American, New York: Academic Press.

[21] Friedberg, R. (2000). "You Can't Take it with you? Immigrant Assimilation and Portability of Human Capital," Journal of Labor Economics, 18(2), pp. 221-251.

[22] Gautier, P. A. (2002). "Search Externalities in a Model with Heterogeneous Jobs and Workers," Economica, 273(1), pp. 21-40.

[23] Hall, R., and P. Milgrom (2008). "The Limited Influence of Unemployment on the Wage Bargain," American Economic Review 98(4), pp. 1653-1674.

[24] Laing, D., T. Palivos, and P. Wang (1995). "Learning, Matching and Growth," Review of Economic Studies 62(1), 115-29.

[25] Laing, D., T. Palivos, and P. Wang (2003). "The Economics of New Blood," Journal of Economic Theory 112(1), 106-56.

[26] Leuven, E., and H. Oosterbeek (2011). "Overeducation and Mismatch in the Labor Market," in E. A. Hanushek, S. Machin and L. Woessmann (eds.), Handbook of the Economics of Education, Amsterdam: Elsevier.

[27] Liu, X. (2010). "On the Macroeconomic and Welfare Effects of Illegal Immigration," Journal of Economic Dynamics and Control 34(12), pp. 2547-2567.

[28] Longva, P., and O. Raaum (2003). "Earnings assimilation of immigrants in Norway: A Reappraisal," Journal of Population Economics 16(1), pp. 177-193.

[29] Nielsen, C. P. (2007). "Immigrant Overeducation: Evidence from Denmark," Policy Research Working Paper Series 4234, The World Bank.

[30] Nieto, S., A. Matano and R. Ramos (2013). "Skill Mismatches in the EU: Immigrants vs. Natives," IZA Discussion Papers 7701, Institute for the Study of Labor.

[31] Ortega, J. (2000). "Pareto-Improving Immigration in an Economy with Equilibrium Unemployment," Economic Journal 110(460), pp. 92-112.

[32] Piracha, M., and F. Vadean (2013). "Migrant Educational Mismatch and the Labor Market," in A. F. Constant and K. F. Zimmermann (eds.), International Handbook of the Economics of Migration, Northampton: Edward Elgar. 
[33] Shimer, R., (2005). "The Cyclical Behavior of Equilibrium Unemployment and Vacancies," American Economic Review 95(1), pp. 25-49. 


\section{A Appendix}

\section{A.1 Proofs}

\section{A.1.1 Restrictions on Parameter Values}

To ensure that all types of workers are employed, all surpluses must be positive. Given the Nash sharing rule this requires that all $\Pi_{i j}^{\kappa}$ are positive. For $\Pi_{L L}^{N}>0$, it is necessary and sufficient to assume that $y_{L}>b_{L}$; similarly, $\Pi_{H H}^{N}>0$, iff $y_{H}>b_{H}$ and $\Pi_{H L}^{I}>0$ iff $\mu y_{L}>b_{H}-(1-\eta) h^{I}$. Given that $\Pi_{L L}^{I}>\Pi_{L L}^{N}, y_{L}>b_{L}$ implies also that $\Pi_{L L}^{I}>0$. Finally, a necessary and sufficient condition for the employability of high-skilled immigrants (EHSI) in high-skill jobs, i.e., $\Pi_{H H}^{I}>0$, is

$$
y_{H}>b_{H}-h^{I}+\frac{\beta m\left(\theta_{L}\right)}{\Psi\left(\theta_{L}\right)+\gamma m\left(\theta_{H}\right)}\left\{\mu y_{L}-\left[b_{H}-(1-\eta) h^{I}\right]\right\} . \quad \text { (Condition for EHSI) }
$$

The Condition for EHSI implies that the output from a match between a skilled immigrant and a skilled vacancy exceeds the worker's outside option.

The assumption that $y_{L}>b_{L}$ guarantees also that $\Pi_{L L}^{N}>V_{L}=0$. Thus, a firm that meets an unskilled native worker will form an employment relation and will not decide to wait for an unskilled immigrant, despite the fact that the latter is willing to accept a lower wage. Moreover, the assumption $\mu y_{L}>b_{H}-(1-\eta) h^{I}$ guarantees the existence of cross-skill matching, since it implies that $\Pi_{H L}^{I}=[(1-\beta) / \beta]\left(E_{H L}^{I}-U_{H}^{I}\right)>0=V_{L}$. Hence, a low-skill position that meets a high-skilled worker prefers to form a match rather than stay vacant and a high-skilled worker who meets a vacant low-skill position prefers to form a match rather than stay unemployed $\left(E_{H L}^{I}>U_{H}^{I}\right)$. Finally, the existence of on-the-job (OTJ) search on behalf of skilled immigrants requires $E_{H H}^{I}>E_{H L}^{I}$. Given the Nash sharing rule, equations (1) and (2) imply that the following condition must hold

$$
y_{H}>b_{H}-h^{I}+\frac{r+s_{H}+\beta \gamma m\left(\theta_{H}\right)+\beta m\left(\theta_{L}\right)}{\Psi\left(\theta_{L}\right)+\gamma m\left(\theta_{H}\right)}\left\{\mu y_{L}-\left[b_{H}-(1-\eta) h^{I}\right]\right\} .
$$

(Condition for OTJ search)

Notice that the Condition for OTJ search is sufficient for the Condition for EHSI to hold.

\section{A.1.2 Proof of Proposition 1}

Recall that $\Omega_{H}=\frac{s_{H}+m_{H}}{s_{H}+\gamma m_{H}}$ and $\Omega_{L}=\frac{s_{H}\left(s_{L}+\gamma m_{H}\right)\left(s_{L}+m_{L}\right)}{s_{L}\left(s_{H}+\gamma m_{H}\right)\left(s_{L}+m_{L}+\gamma m_{H}\right)}$, where to avoid notation clutter, we let $\Psi_{j}=\Psi\left(\theta_{j}\right)=r+s_{j}+\beta m_{j}, j=H, L, m_{j}=m\left(\theta_{j}\right), m_{j}^{\prime}=m^{\prime}\left(\theta_{j}\right)$, and $1-\lambda+I_{L}+I_{H} \Omega_{L}=N$. We denote also the right-hand side of equations (19) and (20) 
as $R H S_{H}$ and $R H S_{L}$, respectively. Differentiating $R H S_{H}$ and $R H S_{L}$ with respect to $\theta_{H}$ and $\theta_{L}$ leads to

$$
\begin{aligned}
& \frac{\partial R H S_{H}}{\partial \theta_{H}}=\frac{(1-\beta) m_{H}^{\prime}}{\lambda+I_{H} \Omega_{H}}\left\{-\frac{\lambda\left(y_{H}-b_{H}\right)}{\Psi_{H}}\left[\frac{(1-\gamma) I_{H} s_{H}}{\left(\lambda+I_{H} \Omega_{H}\right)\left(s_{H}+\gamma m_{H}\right)^{2}}+\frac{\beta}{\Psi_{H}}\right]\right. \\
& +\gamma I_{H}\left[y_{H}-b_{H}+h^{I}-\frac{\beta m_{L}\left[\mu y_{L}-b_{H}+(1-\eta) h^{I}\right]}{\Psi_{L}+\gamma m_{H}}\right] \\
& \frac{\lambda(1-\gamma) s_{H}\left(r+s_{H}+\beta \gamma m_{H}\right)-\beta \gamma \Omega_{H}\left(\lambda+I_{H} \Omega_{H}\right)\left(s_{H}+\gamma m_{H}\right)^{2}}{\left(\lambda+I_{H} \Omega_{H}\right)\left(s_{H}+\gamma m_{H}\right)^{2}\left(r+s_{H}+\beta \gamma m_{H}\right)^{2}} \\
& \left.+\frac{\gamma^{2} I_{H} \Omega_{H} \beta m_{L}\left[\mu y_{L}-b_{H}+(1-\eta) h^{I}\right]}{\left(r+s_{H}+\beta \gamma m_{H}\right)\left(\Psi_{L}+\gamma m_{H}\right)^{2}}\right\} \\
& \frac{\partial R H S_{H}}{\partial \theta_{L}}=-\frac{(1-\beta) \beta \gamma I_{H} \Omega_{H}\left(r+s_{L}+\gamma m_{H}\right)\left[\mu y_{L}-b_{H}+(1-\eta) h^{I}\right]}{\left(\lambda+I_{H} \Omega_{H}\right)\left(r+s_{H}+\beta \gamma m_{H}\right)\left(\Psi_{L}+\gamma m_{H}\right)^{2}} m_{L}^{\prime}<0, \\
& \frac{\partial R H S_{L}}{\partial \theta_{H}}=\frac{\partial \Omega_{L}}{\partial \theta_{H}} \frac{I_{H}(1-\beta)}{N^{2}}\left[\frac{\left[\mu y_{L}-b_{H}+(1-\eta) h^{I}\right]\left(1-\lambda+I_{L}\right)}{\Psi_{L}+\gamma m_{H}}-\frac{\left(1-\lambda+I_{L}\right)\left(y_{L}-b_{L}\right)+I_{L} h^{I}}{\Psi_{L}}\right] \\
& -\frac{(1-\beta) I_{H} \Omega_{L}\left[\mu y_{L}-b_{H}+(1-\eta) h^{I}\right] \gamma m_{H}^{\prime}}{N\left(\Psi_{L}+\gamma m_{H}\right)^{2}} \\
& =\frac{(\beta-1) I_{H} \Omega_{L} \gamma m_{H}^{\prime}}{N}\left\{\frac { \Pi } { N } \left[\frac{\left[\mu y_{L}-b_{H}+(1-\eta) h^{I}\right]\left(1-\lambda+I_{L}\right)}{\Psi_{L}+\gamma m_{H}}\right.\right. \\
& \left.\left.-\frac{\left(1-\lambda+I_{L}\right)\left(y_{L}-b_{L}\right)+I_{L} h^{I}}{\Psi_{L}}\right]+\frac{\mu y_{L}-b_{H}+(1-\eta) h^{I}}{\left(\Psi_{L}+\gamma m_{H}\right)^{2}}\right\}
\end{aligned}
$$

and

$$
\begin{aligned}
\frac{\partial R H S_{L}}{\partial \theta_{L}}= & \frac{\partial \Omega_{L}}{\partial \theta_{L}} \frac{(1-\beta) I_{H}}{N^{2}}\left[\frac{\left[\mu y_{L}-b_{H}+(1-\eta) h^{I}\right]\left(1-\lambda+I_{L}\right)}{\Psi_{L}+\gamma m_{H}}-\frac{\left(1-\lambda+I_{L}\right)\left(y_{L}-b_{L}\right)+I_{L} h^{I}}{\Psi_{L}}\right] \\
& -\frac{(1-\beta) \beta m_{L}^{\prime}}{N}\left[\frac{\left(1-\lambda+I_{L}\right)\left(y_{L}-b_{L}\right)+I_{L} h^{I}}{\Psi_{L}^{2}}+\frac{\left[\mu y_{L}-b_{H}+(1-\eta) h^{I}\right] I_{H} \Omega_{L}}{\left(\Psi_{L}+\gamma m_{H}\right)^{2}}\right],
\end{aligned}
$$

where $\Pi=\frac{\left(s_{L}-s_{H}\right)\left(s_{L}+m_{L}+\gamma m_{H}\right)^{2}+m_{L}\left(s_{H}+\gamma m_{H}\right)^{2}}{\left(s_{L}+\gamma m_{H}\right)\left(s_{L}-s_{H}+m_{L}\right)\left(s_{H}+\gamma m_{H}\right)\left(s_{L}+m_{L}+\gamma m_{H}\right)}, \frac{\partial \Omega_{L}}{\partial \theta_{L}}=\frac{s_{H}\left(s_{L}+\gamma m_{H}\right) \gamma m_{H} m_{L}^{\prime}}{s_{L}\left(s_{H}+\gamma m_{H}\right)\left(s_{L}+m_{L}+\gamma m_{H}\right)^{2}}>0$.

Since the left-hand side of equation (19) $\left(L H S_{H}\right)$ increases in $\theta_{H}$, a sufficient condition for the existence of solution to $\theta_{H}$, given $\theta_{L}$, is $\frac{\partial R H S_{H}}{\partial \theta_{H}}<0, \frac{c_{H}}{q(0)} \leq\left. R H S_{H}\right|_{\theta_{H}=0}$ and $\frac{c_{H}}{q(+\infty)} \geq$ $\left.R H S_{H}\right|_{\theta_{H}=+\infty}$. Moreover, $\frac{\partial R H S_{H}}{\partial \theta_{L}}<0$ implies $\frac{\partial \theta_{H}}{\partial \theta_{L}}<0$ in equation (19). In addition, since $q^{\prime}(\theta)<0, q(0)=+\infty, q(+\infty)=0, m^{\prime}(\theta)>0, m(0)=0$ and $m(+\infty)=+\infty$, the conditions $\frac{c_{H}}{q(0)} \leq\left. R H S_{H}\right|_{\theta_{H}=0}$ and $\frac{c_{H}}{q(+\infty)} \geq\left. R H S_{H}\right|_{\theta_{H}=+\infty}$ always hold and the solution to $\theta_{H}$ given $\theta_{L}$ satisfies $\theta_{H}\left(\theta_{L}\right) \in\left(\underline{\theta_{H}}, \overline{\theta_{H}}\right]$, where $0 \leq \underline{\theta_{H}}<\overline{\theta_{H}}<+\infty$. 
Similarly, since the left-hand side of equation $(20)\left(L H S_{L}\right)$ increases in $\theta_{L}$, a sufficient condition for the existence of solution to $\theta_{L}$ given $\theta_{H}$ is $\frac{\partial R H S_{L}}{\partial \theta_{L}}<0, \frac{c_{L}}{q(0)} \leq\left. R H S_{L}\right|_{\theta_{L}=0}$ and $\frac{c_{L}}{q(+\infty)} \geq\left. R H S_{L}\right|_{\theta_{L}=+\infty}$. Moreover, if $\frac{\partial R H S_{L}}{\partial \theta_{H}}>0$ then $\frac{\partial \theta_{L}}{\partial \theta_{H}}>0$ in equation (20). In addition, since $q^{\prime}(\theta)<0, q(0)=+\infty, q(+\infty)=0, m^{\prime}(\theta)>0, m(0)=0$ and $m(+\infty)=+\infty$, the conditions $\frac{c_{L}}{q(0)} \leq\left. R H S_{L}\right|_{\theta_{L}=0}$ and $\frac{c_{L}}{q(+\infty)} \geq\left. R H S_{L}\right|_{\theta_{L}=+\infty}$ always hold and the solution to $\theta_{L}$, given $\theta_{H}$, satisfies $\theta_{L}\left(\theta_{H}\right) \in\left[\underline{\theta_{L}}, \overline{\theta_{L}}\right)$, where $0 \leq \underline{\theta_{L}}<\overline{\theta_{L}}<+\infty$.

Thus, if we impose the above conditions on parameters, the $\theta_{H^{-}} \theta_{L}$ curve described by equation (19) decreases in $\theta_{L}$, whereas the one described by equation (20) increases; it follows that they intersect once. Hence, the steady-state equilibrium exists and is unique. The above conditions imply

$$
\begin{gathered}
\left\{-\frac{\lambda\left(y_{H}-b_{H}\right)}{\Psi_{H}}\left[\frac{(1-\gamma) I_{H} s_{H}}{\left(\lambda+I_{H} \Omega_{H}\right)\left(s_{H}+\gamma m_{H}\right)^{2}}+\frac{\beta}{\Psi_{H}}\right]\right. \\
+\gamma I_{H}\left[y_{H}-b_{H}+h^{I}-\frac{\beta m_{L}\left[\mu y_{L}-b_{H}+(1-\eta) h^{I}\right]}{\Psi_{L}+\gamma m_{H}}\right] \\
\frac{\lambda(1-\gamma) s_{H}\left(r+s_{H}+\beta \gamma m_{H}\right)-\beta \gamma \Omega_{H}\left(\lambda+I_{H} \Omega_{H}\right)\left(s_{H}+\gamma m_{H}\right)^{2}}{\left(\lambda+I_{H} \Omega_{H}\right)\left(s_{H}+\gamma m_{H}\right)^{2}\left(r+s_{H}+\beta \gamma m_{H}\right)^{2}} \\
\left.+\frac{\gamma^{2} I_{H} \Omega_{H} \beta m_{L}\left[\mu y_{L}-b_{H}+(1-\eta) h^{I}\right]}{\left(r+s_{H}+\beta \gamma m_{H}\right)\left(\Psi_{L}+\gamma m_{H}\right)^{2}}\right\}<0, \\
\frac{\left.\Pi \mu y_{L}-b_{H}+(1-\eta) h^{I}\right]\left(1-\lambda+I_{L}\right)}{\Psi_{L}+\gamma m_{H}}\left[\frac{\left(1-\lambda+I_{L}\right)\left(y_{L}-b_{L}\right)+I_{L} h^{I}}{\Psi_{L}}<0,\right. \\
\left.\Psi_{L}-b_{H}+(1-\eta) h^{I}\right]\left(1-\lambda+I_{L}\right) \\
\Psi_{L}+\gamma m_{H}
\end{gathered}
$$

After some tedious algebra, we finally get the following sufficient conditions:

$$
\begin{aligned}
& I_{H}\left\{\left(y_{H}-b_{H}+h^{I}\right)\left[\frac{\lambda(1-\gamma)\left(r+s_{H}\right)}{\left(\lambda+I_{H}\right) s_{H}}-\beta \gamma^{2}\right]+\left[\mu y_{L}-b_{H}+(1-\eta) h^{I}\right]\left(1+\beta \gamma^{2}\right)\right\} \\
&<\lambda\left(y_{H}-b_{H}\right) \min (\gamma, \beta), \frac{\left[\mu y_{L}-b_{H}+(1-\eta) h^{I}\right]\left(1-\lambda+I_{L}\right)}{\left(1-\lambda+I_{L}\right)\left(y_{L}-b_{L}\right)+I_{L} h^{I}}<1, \\
& \frac{\Pi^{*}}{1-\lambda+I_{L}+I_{H}}\left[\frac{\left(1-\lambda+I_{L}\right)\left[\mu y_{L}-b_{H}+(1-\eta) h^{I}-\left(y_{L}-b_{L}\right)\right]-I_{L} h^{I}}{r+s_{L}}\right]+\frac{\mu y_{L}-b_{H}}{r+s_{L}}<0,
\end{aligned}
$$

where $\Pi^{*}=\frac{s_{L}-s_{H}}{\left(s_{L}+\gamma \bar{m}_{H}\right)\left(s_{H}+\gamma \bar{m}_{H}\right)}, \bar{m}_{H}=m_{H}\left(\overline{\theta_{H}}\right)$ and $\overline{\theta_{H}}$ is the solution to

$$
\frac{c_{H}}{q\left(\theta_{H}\right)}=\frac{1-\beta}{\lambda+I_{H} \Omega_{H}}\left[\frac{\lambda\left(y_{H}-b_{H}\right)}{\Psi_{H}}+\frac{\gamma I_{H} \Omega_{H}}{r+s_{H}+\beta \gamma m_{H}}\left[y_{H}-b_{H}+h^{I}\right]\right] \text {. }
$$

It is clear that for sufficiently large $h^{I}, \gamma$ and $\eta$, the above inequalities can all hold. Under the above three parameter restrictions, there exists a unique steady-state equilibrium. 


\section{A.1.3 Proof of Proposition 2}

a) The effects on $w_{H H}^{N}, w_{L L}^{N}, w_{L L}^{I}$ and $w_{H L}^{I}$ follow immediately upon differentiation of (13), (14) and (15). Moreover, differentiating (16) yields

$$
\begin{aligned}
\frac{d w_{H H}^{I}}{d \theta_{H}}= & \frac{\beta(1-\beta) \gamma m_{H}^{\prime}\left(r+s_{H}\right)}{\left(r+s_{H}+\beta \gamma m_{H}\right)^{2}}\left\{y_{H}-b_{H}+h^{I}\right. \\
& \left.-m_{L} \frac{\beta\left(\Psi_{L}+\gamma m_{H}\right)+r+s_{H}+\beta \gamma m_{H}}{\left(\Psi_{L}+\gamma m_{H}\right)^{2}}\left[\mu y_{L}-b_{H}+(1-\eta) h^{I}\right]\right\}
\end{aligned}
$$

which can take either sign. Finally, the effect of $\theta_{L}$ on $w_{H H}^{I}$ follows immediately after differentiating (16).

b) The results follow after differentiating equations (17). In particular,

$$
\frac{d u_{H}^{I}}{d \theta_{H}}=\frac{I_{H} s_{H} \gamma m_{H}^{\prime}\left[m_{L}\left(s_{H}-s_{L}\right)-\left(s_{L}+\gamma m_{H}\right)^{2}\right]}{\left(s_{H}+\gamma m_{H}\right)^{2}\left(s_{L}+m_{L}+\gamma m_{H}\right)^{2}}<0 \text { if } s_{H}<s_{L} .
$$

\section{A.1.4 Proof of Proposition 3}

a) Given that lower $\theta_{H}$ leads to a lower wage $w_{H H}^{N}$ and higher unemployment rate, $u_{H}^{N} / \lambda$, (see Proposition 2), it suffices to show that in the cross-skill matching equilibrium the value of $\theta_{H}$ is lower than the one in the ex post segmentation equilibrium. In the latter equilibrium, the equation that sets the average cost of a high-skilled position equal to the value of the profit expected from such a position is

$$
\frac{c_{H}}{q_{H}}=\frac{1-\beta}{\lambda+I_{H} \Omega_{H}}\left(\frac{\lambda\left(y_{H}-b_{H}\right)}{\Psi_{H}}+\frac{\gamma I_{H} \Omega_{H}\left(y_{H}-b_{H}+h^{I}\right)}{r+s_{H}+\beta \gamma m_{H}}\right) .
$$

This follows simply by setting $\mu y_{L}=b_{H}-(1-\eta) h^{I}$ in equation (19). Denote the values of $\theta_{H}$ and $\theta_{L}$ that satisfy equation equation (A.1) as $\theta_{H}^{N C S M}$ and $\theta_{L}^{N C S M}$, and denote the solutions when there is cross-skill matching as $\theta_{H}^{C S M}$ and $\theta_{L}^{C S M}$ ((N)CSM stands for (no) cross-skill matching). From the proof of Proposition 1, we know that $\theta_{H}^{N C S M}=\overline{\theta_{H}}>$ $\theta_{H}^{C S M}$

b) In the ex post segmentation equilibrium the equation that replaces (20) is

$$
\left.\frac{\Psi\left(\theta_{L}\right)}{q\left(\theta_{L}\right)}\right|_{N C S M}=\frac{1-\beta}{c_{L}}\left(y_{L}-b_{L}+\frac{I_{L} h^{I}}{1-\lambda+I_{L}}\right) .
$$

Note that, unlike what we did in case a) above, one cannot just set $\mu y_{L}=b_{H}-(1-\eta) h^{I}$ in equation (20); one should also take into account that in the ex post segmentation equilibrium, where there is no cross-skill matching, there is also no on-the-job search by 
mismatched workers. Hence, to obtain (A.2), one should substitute equations (1) and the free-entry condition (equation 11) in (4). Next, if $\mu=1$, we have that

$$
\begin{aligned}
\left.\frac{\Psi_{L}}{q_{L}}\right|_{C S M}= & \frac{1-\beta}{c_{L}\left(1-\lambda+I_{L}+I_{H} \Omega_{L}\right)}\left\{\left(1-\lambda+I_{L}\right)\left(y_{L}-b_{L}\right)+I_{L} h^{I}\right. \\
& \left.+\frac{I_{H} \Omega_{L}\left[y_{L}-b_{H}+(1-\eta) h^{I}\right] \Psi_{L}}{\Psi_{L}+\gamma m_{H}}\right\} \\
< & \frac{1-\beta}{c_{L}}\left[y_{L}-b_{L}+\frac{I_{L} h^{I}}{1-\lambda+I_{L}}-\frac{I_{H} \Omega_{L}\left[b_{H}-(1-\eta) h^{I}-b_{L}\right]}{1-\lambda+I_{L}+I_{H} \Omega_{L}}\right] .
\end{aligned}
$$

If $b_{H}-(1-\eta) h^{I}>b_{L}$, we have

$$
\left.\frac{\Psi\left(\theta_{L}\right)}{q\left(\theta_{L}\right)}\right|_{C S M}<\left.\frac{\Psi\left(\theta_{L}\right)}{q\left(\theta_{L}\right)}\right|_{N C S M} .
$$

Since $\Psi\left(\theta_{L}\right) / q\left(\theta_{L}\right)$ is increasing in $\theta_{L}$, the result follows.

\section{A.1.5 Proof of Proposition 4}

a) Differentiating equations (19) and (20) we get

$$
\left[\begin{array}{cc}
\frac{\partial R H S_{H}}{\partial \theta_{H}}+\frac{c_{H} q^{\prime}\left(\theta_{H}\right)}{q^{2}\left(\theta_{H}\right)} & \frac{\partial R H S_{H}}{\partial \theta_{L}} \\
\frac{\partial R H S_{L}}{\partial \theta_{H}} & \frac{\partial R H S_{L}}{\partial \theta_{L}}+\frac{c_{L} q^{\prime}\left(\theta_{L}\right)}{q^{2}\left(\theta_{L}\right)}
\end{array}\right]\left[\begin{array}{c}
\frac{d \theta_{H}}{d I_{L}} \\
\frac{d \theta_{L}}{d I_{L}}
\end{array}\right]=\left[\begin{array}{c}
-\frac{\partial R H S_{H}}{\partial I_{L}} \\
-\frac{\partial R H S_{L}}{\partial I_{L}}
\end{array}\right]
$$

where

$$
\begin{gathered}
\frac{\partial R H S_{H}}{\partial I_{L}}=0, \\
\frac{\partial R H S_{L}}{\partial I_{L}}=\frac{1-\beta}{N^{2}}\left[\frac{I_{H} \Omega_{L}\left(y_{L}-b_{L}\right)+\left(1-\lambda+I_{H} \Omega_{L}\right) h^{I}}{\Psi_{L}}\right. \\
\left.-\frac{I_{H} \Omega_{L}\left[\mu y_{L}-b_{H}+(1-\eta) h^{I}\right]}{\Psi_{L}+\gamma m_{H}}\right] \\
>\quad \frac{(1-\beta) h^{I}}{N^{2} \Psi_{L}}\left[1-\lambda+I_{H} \Omega_{L}-\frac{I_{H} \Omega_{L} I_{L}}{1-\lambda+I_{L}}\right]>0 .
\end{gathered}
$$

Recall from the proof of Proposition 1 that $\frac{\partial R H S_{H}}{\partial \theta_{L}}<0$. Assume also that $\frac{\partial R H S_{H}}{\partial \theta_{H}}<0$, $\frac{\partial R H S_{L}}{\partial \theta_{H}}>0, \frac{\partial R H S_{L}}{\partial \theta_{L}}<0$ to ensure existence and uniqueness of a steady-state equilibrium (see the proof of Proposition 1). It follows then that the determinant of the coefficient matrix in (A.3) is positive. Hence, applying Crammer's rule we get that $\frac{d \theta_{H}}{d I_{L}}<0$ and 
$\frac{d \theta_{L}}{d I_{L}}>0$. The rest of the proposition, i.e., the fact that low-skilled natives benefit and high-skilled lose, follows from Proposition 2.

b) Differentiating equations (19) and (20) we get

$$
\left[\begin{array}{cc}
\frac{\partial R H S_{H}}{\partial \theta_{H}}+\frac{c_{H} q^{\prime}\left(\theta_{H}\right)}{q^{2}\left(\theta_{H}\right)} & \frac{\partial R H S_{H}}{\partial \theta_{L}} \\
\frac{\partial R H S_{L}}{\partial \theta_{H}} & \frac{\partial R H S_{L}}{\partial \theta_{L}}+\frac{c_{L} q^{\prime}\left(\theta_{L}\right)}{q^{2}\left(\theta_{L}\right)}
\end{array}\right]\left[\begin{array}{c}
\frac{d \theta_{H}}{d I_{H}} \\
\frac{d \theta_{L}}{d I_{H}}
\end{array}\right]=\left[\begin{array}{c}
-\frac{\partial R H S_{H}}{\partial I_{H}} \\
-\frac{\partial R H S_{L}}{\partial I_{H}}
\end{array}\right]
$$

where

$$
\begin{aligned}
\frac{\partial R H S_{H}}{\partial I_{H}}= & \frac{(1-\beta) \lambda \Omega_{H}}{\left(\lambda+I_{H} \Omega_{H}\right)^{2}}\left\{\frac { \gamma } { r + s _ { H } + \beta \gamma m _ { H } } \left[y_{H}-b_{H}+h^{I}\right.\right. \\
& \left.\left.-\frac{\beta m_{L}\left[\mu y_{L}-b_{H}+(1-\eta) h^{I}\right]}{\Psi_{L}+\gamma m_{H}}\right]-\frac{y_{H}-b_{H}}{\Psi_{H}}\right\} \\
\frac{\partial R H S_{L}}{\partial I_{H}}= & \frac{(1-\beta) \Omega_{L}}{N^{2}}\left\{\frac{\left[\mu y_{L}-b_{H}+(1-\eta) h^{I}\right]\left(1-\lambda+I_{L}\right)}{\Psi_{L}+\gamma m_{H}}\right. \\
& \left.-\frac{\left(1-\lambda+I_{L}\right)\left(y_{L}-b_{L}\right)+I_{L} h^{I}}{\Psi_{L}}\right\},
\end{aligned}
$$

Under the same assumptions as in part a), the determinant of the coefficient matrix is positive. If $\gamma \rightarrow 1$ and $h^{I}-\frac{\beta m_{L}\left[\mu y_{L}-b_{H}+(1-\eta) h^{I}\right]}{\Psi_{L}+\gamma m_{H}}>0$, we get $\frac{\partial R H S_{H}}{\partial I_{H}}>0$. If $\gamma \rightarrow 0$, we get $\frac{\partial R H S_{H}}{\partial I_{H}}<0$. Moreover, if $\mu=1$, we have $\frac{\partial R H S_{L}}{\partial I_{H}}<0$. Hence, applying Crammer's rule we get that if $\gamma \rightarrow 1, \mu=1$ and $h^{I}-\frac{\beta m_{L}\left[\mu y_{L}-b_{H}+(1-\eta) h^{I}\right]}{\Psi_{L}+\gamma m_{H}}>0, \frac{d \theta_{H}}{d I_{H}}>0$, while $\frac{d \theta_{L}}{d I_{H}}$ has an ambiguous sign. If $\gamma \rightarrow 0$, we get $\frac{d \theta_{L}}{d I_{H}}<0$ and $\frac{d \theta_{H}}{d I_{H}}$ has once again an ambiguous sign.

\section{A.2 Sensitivity Analysis}

In this section we perform sensitivity analysis with respect to the parameter values of the relativity productivity $\mu$, the replacement ratio, which is equal to $b_{H} / w_{H H}^{N}=b_{L} / w_{L L}^{N}$, and the relative search cost faced by mismatched workers, $\eta$. We present the case where there is a change just in one parameter value, and all others remain the same, as well as the case where, after changing one parameter value, the model is recalibrated to match all targets. $^{21}$

\footnotetext{
${ }^{21}$ For the cases where we analyze the sensitivity with respect to $\mu$ and $\eta$, we do not re-examine the effects of cross-skill matching. We do this because, as explained in the main text, to get the ex post segmentation equilibrium we change $\mu$ and $\eta$ so that $\mu y_{L}=b_{H}-(1-\eta) h^{I}$. Further changes then in $\mu$ or $\eta$ do not alter the equilibrium. Also, for the case where we examine the sensitivity with respect to the replacement ratio, we look only at the case where the model is recalibrated to match all targets. We do this, because a change in the replacement ratio triggers a change in more than one parameter, namely, a change in both $b_{H}$ and $b_{L}$.
} 


\section{A.2.1 Relative Productivity}

In Tables A.1 and A.2 we present the results for the case where we change the value for the relative productivity parameter $\mu$ but keep all other parameter values the same. Table A.1 below presents the results after $a$ ) a change in unskilled immigration only, which is of the same magnitude as the one found in the data, i.e., $\Delta I_{L}=0.051$ (second column in Table A.1) b) a change in skilled immigration equal to $\Delta I_{H}=0.026$ (third column) and finally $c$ ) an immigration influx that is of the same magnitude and composition as the one in the data, i.e., $\Delta I_{L}=0.051$ and $\Delta I_{H}=0.026$ (last column). Notice that the differences between Tables 4 , in the main text, and A.1 are qualitatively in the same direction and quantitatively small.

Table A.1: The Effects of the 2000-2009 Immigration Influx

$$
\mu=1.2
$$

(Percentage Changes)

\begin{tabular}{|c|c|c|c|}
\hline Variable & $I_{L}$ & $I_{H}$ & $I_{L}$ and $I_{H}$ \\
\hline \multicolumn{4}{|c|}{ Unskilled Natives } \\
\hline Wage $\left(w_{L L}^{N}\right)$ & 0.24 & 0.05 & 0.26 \\
\hline Unemployment Rate $\left(\frac{u_{L}^{N}}{1-\lambda}\right)$ & -7.69 & -0.70 & -8.11 \\
\hline Labor Market Tightness $\left(\theta_{L}\right)$ & 18.53 & 1.50 & 19.69 \\
\hline \multicolumn{4}{|c|}{$\begin{array}{l}\text { Skilled Natives } \\
\end{array}$} \\
\hline Wage $\left(w_{H H}^{N}\right)$ & -0.01 & 0.02 & 0.04 \\
\hline Unemployment Rate $\left(\frac{u_{H}^{N}}{\lambda}\right)$ & 0.58 & -3.96 & -3.32 \\
\hline Labor Market Tightness $\left(\theta_{H}\right)$ & -1.17 & 8.61 & 7.15 \\
\hline \multicolumn{4}{|c|}{$\begin{array}{ll}\text { Overall Natives } \\
\end{array}$} \\
\hline Wage & 0.09 & 0.04 & 0.13 \\
\hline Unemployment Rate & -5.42 & -1.59 & -6.80 \\
\hline Surplus1 & 0.95 & 0.34 & 1.26 \\
\hline Surplus2 & 1.12 & 0.37 & 1.46 \\
\hline \multicolumn{4}{|c|}{ Unskilled Immigrants } \\
\hline Wage $\left(w_{L L}^{I}\right)$ & 1.97 & 0.18 & 2.07 \\
\hline Unemployment Rate $\left(\frac{u_{L}^{I}}{I_{L}}\right)$ & -7.69 & -0.70 & -8.11 \\
\hline \multicolumn{4}{|c|}{ Skilled Immigrants } \\
\hline Wage $\left(w_{H H}^{I}\right)$ & 0.48 & 0.95 & 1.38 \\
\hline Employment Rate $\left(\frac{e_{H H}^{I}}{I_{H}}\right)$ & -0.14 & 0.95 & 0.80 \\
\hline Wage $\left(w_{H L}^{I}\right)$ & 1.71 & -0.36 & 1.33 \\
\hline Overeducation Ratio $\left(\frac{e_{H L}^{I}}{I_{H}}\right)$ & 1.53 & -3.48 & -1.92 \\
\hline \multicolumn{4}{|c|}{$\begin{array}{l}\text { Overall Skilled Immigrants } \\
\end{array}$} \\
\hline Wage & 0.67 & 0.81 & 1.43 \\
\hline Unemployment Rate $\left(\frac{u_{H}^{I}}{I_{H}}\right)$ & -6.86 & -1.52 & -8.04 \\
\hline \multicolumn{4}{|c|}{ Overall Immigrants } \\
\hline Wage & -1.07 & 4.36 & 2.42 \\
\hline Unemployment Rate & -0.72 & -10.67 & -8.58 \\
\hline
\end{tabular}


Table A.2 presents the results from an improvement in the transferability of foreign human capital. As in the main text, in all cases, the initial situation is a value of $\gamma=0.077$ (overeducation ratio for high-skilled immigrants 20.5 percent). ${ }^{22}$ The differences between Tables 5 and A.2 are qualitatively in the same direction and quantitatively small.

Table A.2: The Effects of a Change in the Transferability of Human Capital (Percentage Changes)

\begin{tabular}{lc|c|c|c}
\hline Variable & $\gamma=0.06$ & $\gamma=0.10$ & $\gamma=0.20$ & $\gamma=0.80$ \\
\hline Overeducation Ratio $(\%)$ & 25.2 & 15.6 & 7.3 & 1.3 \\
\hline Unskilled Natives \\
\hline Wage $\left(w_{L L}^{N}\right)$ & 0.01 & -0.01 & -0.02 & -0.04 \\
\hline Unemployment Rate $\left(\frac{u_{L}^{N}}{1-\lambda}\right)$ & -0.19 & 0.19 & 0.68 & 1.26 \\
\hline Labor Market Tightness $\left(\theta_{L}\right)$ & 0.40 & -0.41 & -1.42 & -2.64 \\
\hline \multicolumn{5}{c}{ Skilled Natives } \\
\hline Wage $\left(w_{H H}^{N}\right)$ & -0.07 & 0.05 & 0.09 & -0.02 \\
\hline Unemployment Rate $\left(\frac{u_{H}^{N}}{\lambda}\right)$ & 4.96 & -3.51 & -6.92 & 1.23 \\
\hline Labor Market Tightness $\left(\theta_{H}\right)$ & -9.44 & 7.61 & 15.80 & -2.47 \\
\hline \multicolumn{5}{c}{ Overall Natives } \\
\hline Wage & -0.04 & 0.03 & 0.04 & -0.03 \\
\hline Unemployment Rate & 1.23 & -0.83 & -1.41 & 1.25 \\
\hline Surplus1 10.01 & -0.01 & -0.11 & -0.37 \\
\hline Surplus2 & -0.03 & -0.00 & -0.10 & -0.41 \\
\hline Unskilled Immigrants \\
\hline Wage $\left(w_{L L}^{I}\right)$ & 0.05 & -0.05 & -0.17 & -0.32 \\
\hline Unemployment Rate $\left(\frac{u_{L}^{I}}{I_{L}}\right)$ & -0.19 & 0.19 & 0.68 & 1.26 \\
\hline \multicolumn{5}{c|}{ Skilled Immigrants } \\
\hline Wage $\left(w_{H H}^{I}\right)$ & -6.59 & 6.29 & 20.07 & 35.87 \\
\hline Employment Rate $\left(\frac{e_{H H}^{I}}{I_{H}}\right)$ & -7.61 & 6.35 & 17.62 & 26.72 \\
\hline Wage $\left(w_{H L}^{I}\right)$ & 3.38 & -4.01 & -16.93 & -44.01 \\
\hline Overeducation Ratio $\left(\frac{e_{H L}^{I}}{I_{H}}\right)$ & 28.67 & -23.67 & -64.58 & -93.75 \\
\hline Overall Skilled Immigrants \\
\hline Wage & -6.59 & 6.29 & 19.80 & 38.45 \\
\hline Unemployment Rate & 6.49 & -6.31 & -22.43 & -54.90 \\
\hline Wage & -1.76 & 5.54 & 7.08 & 13.91 \\
\hline Unemployment Rate & 0.49 & -0.44 & -1.49 & -4.10 \\
\hline
\end{tabular}

Next we present the case where we set the value of the relative productivity parameter $\mu=1.2$ and then recalibrate the model to match all targets. Table A.3 presents the new parameter values (only the values of $c_{H}, c_{L}$, and $h^{I}$ change).

${ }^{22}$ When $\mu$ changes from 1.0 to 1.2 and $\gamma$ remains 0.0739 , the overeducation changes from 20 to $20.5 \%$ 
Table A.3: Values of the Calibrated Parameters

\begin{tabular}{ll}
\hline Value & Interpretation \\
\hline \hline$c_{L}=1.229, c_{H}=3.578$ & Vacancy costs \\
$A_{L}=0.665, A_{H}=1.463$ & Matching efficiency parameters \\
$h^{I}=3.084$ & Search cost \\
$y_{H}=1.579$ & Relative productivity of high-skilled workers \\
$b_{L}=0.484, b_{H}=0.779$ & Unemployment flow incomes \\
$\gamma=0.077$ & Transferability of foreign human capital \\
\hline
\end{tabular}

Table A.4 presents the effects of a change in immigration equal to that found in the data. The differences between Tables 4, A.1 and A.4 are qualitatively in the same direction and quantitatively small.

Table A.4: The Effects of the 2000-2009 Immigration Influx

(Percentage Changes)

\begin{tabular}{|c|c|c|c|}
\hline Variable & $I_{L}$ & $I_{H}$ & $I_{L}$ and $I_{H}$ \\
\hline \multicolumn{4}{|c|}{ Unskilled Natives } \\
\hline Wage $\left(w_{L L}^{N}\right)$ & 0.25 & 0.02 & 0.27 \\
\hline Unemployment Rate $\left(\frac{u_{L}^{N}}{1-\lambda}\right)$ & -7.98 & -0.72 & -8.42 \\
\hline Labor Market Tightness $\left(\theta_{L}\right)$ & 19.32 & 1.55 & 20.54 \\
\hline \multicolumn{4}{|c|}{$\begin{array}{ll}\text { Skilled Natives } \\
\end{array}$} \\
\hline Wage $\left(w_{H H}^{N}\right)$ & -0.01 & 0.06 & 0.05 \\
\hline Unemployment Rate $\left(\frac{u_{H}^{N}}{\lambda}\right)$ & 0.62 & -4.36 & -3.68 \\
\hline Labor Market Tightness $\left(\theta_{H}\right)$ & -1.25 & 9.53 & 7.97 \\
\hline \multicolumn{4}{|c|}{ Overall Natives } \\
\hline Wage & 0.10 & 0.04 & 0.13 \\
\hline Unemployment Rate & -5.68 & -1.70 & -7.15 \\
\hline Surplus1 & 1.01 & 0.35 & 1.33 \\
\hline Surplus2 & 1.19 & 0.39 & 1.55 \\
\hline \multicolumn{4}{|c|}{ Unskilled Immigrants } \\
\hline Wage $\left(w_{L L}^{I}\right)$ & 2.20 & 0.20 & 2.33 \\
\hline Unemployment Rate $\left(\frac{u_{L}^{I}}{I_{L}}\right)$ & -7.98 & -0.72 & -8.42 \\
\hline \multicolumn{4}{|c|}{ Skilled Immigrants } \\
\hline Wage $\left(w_{H H}^{I}\right)$ & 0.53 & 1.12 & 1.60 \\
\hline Employment Rate $\left(\frac{e_{H H}^{I}}{I_{H}}\right)$ & -0.14 & 1.03 & 0.87 \\
\hline Wage $\left(w_{H L}^{I}\right)$ & 1.94 & -0.45 & 1.46 \\
\hline Overeducation Ratio $\left(\frac{e_{H L}^{I}}{I_{H}}\right)$ & 1.64 & -3.87 & -2.21 \\
\hline \multicolumn{4}{|c|}{ Overall Skilled Immigrants } \\
\hline Wage & 0.74 & 0.96 & 1.64 \\
\hline Unemployment Rate $\left(\frac{u_{H}^{I}}{I_{H}}\right)$ & -7.09 & -1.64 & -8.37 \\
\hline \multicolumn{4}{|c|}{ Overall Immigrants } \\
\hline Wage & -0.86 & 4.42 & 2.66 \\
\hline Unemployment Rate & -0.98 & -10.75 & -8.86 \\
\hline
\end{tabular}

Table A.5 presents the effects from a change in the transferability of foreign human 
capital. The initial state is the one where $\gamma=0.077$ (overeducation ratio for high-skilled immigrants 20\%). The differences between Tables 5, A.2 and A.5 are qualitatively in the same direction and quantitatively small.

Table A.5: The Effects of a Change in the Transferability of Human Capital (Percentage Changes)

\begin{tabular}{|c|c|c|c|c|}
\hline Variable & $\gamma=0.06$ & $\gamma=0.10$ & $\gamma=0.20$ & $\gamma=0.60$ \\
\hline Overeducation Ratio (\%) & 25.8 & 15.2 & 7.1 & 1.3 \\
\hline \multicolumn{5}{|c|}{ Unskilled Natives } \\
\hline Wage $\left(w_{L L}^{N}\right)$ & 0.01 & -0.01 & -0.02 & -0.04 \\
\hline Unemployment Rate $\left(\frac{u_{L}^{N}}{1-\lambda}\right)$ & -0.19 & 0.20 & 0.70 & 1.30 \\
\hline Labor Market Tightness $\left(\theta_{L}\right)$ & 0.41 & -0.42 & -1.47 & -2.71 \\
\hline \multicolumn{5}{|c|}{$\begin{array}{l}\text { Skilled Natives } \\
\end{array}$} \\
\hline Wage $\left(w_{H H}^{N}\right)$ & -0.06 & 0.04 & 0.08 & -0.03 \\
\hline Unemployment Rate $\left(\frac{u_{H}^{N}}{\lambda}\right)$ & 4.88 & -3.42 & -6.48 & 2.59 \\
\hline Labor Market Tightness $\left(\theta_{H}\right)$ & -9.30 & 7.37 & 14.67 & -5.10 \\
\hline \multicolumn{5}{|c|}{$\begin{array}{ll}\text { Overall Natives } \\
\end{array}$} \\
\hline Wage & -0.03 & 0.02 & 0.04 & -0.04 \\
\hline Unemployment Rate & 1.17 & -0.77 & -1.22 & 1.65 \\
\hline Surplus1 & -0.00 & -0.02 & -0.13 & -0.40 \\
\hline Surplus2 & -0.02 & -0.01 & -0.11 & -0.45 \\
\hline \multicolumn{5}{|c|}{ Unskilled Immigrants } \\
\hline Wage $\left(w_{L L}^{I}\right)$ & 0.05 & -0.05 & -0.19 & -0.36 \\
\hline Unemployment Rate $\left(\frac{u_{L}^{I}}{I_{L}}\right)$ & -0.19 & 0.20 & 0.70 & 1.30 \\
\hline \multicolumn{5}{|c|}{ Skilled Immigrants } \\
\hline Wage $\left(w_{H H}^{I}\right)$ & -7.08 & 6.74 & 21.41 & 38.17 \\
\hline Employment Rate $\left(\frac{e_{H H}^{I}}{I_{H}}\right)$ & -7.45 & 6.19 & 17.14 & 25.98 \\
\hline Wage $\left(w_{H L}^{I}\right)$ & 3.70 & -4.38 & -18.36 & -47.28 \\
\hline Overeducation Ratio $\left(\frac{e_{H L}^{I}}{I_{H}}\right)$ & 28.88 & -23.75 & -64.66 & -93.73 \\
\hline \multicolumn{5}{|c|}{ Overall Skilled Immigrants } \\
\hline Wage & -5.31 & 5.90 & 20.99 & 40.66 \\
\hline Unemployment Rate & 6.51 & -6.32 & -22.51 & -55.01 \\
\hline \multicolumn{5}{|c|}{ Overall Immigrants } \\
\hline Wage & -1.88 & 2.09 & 7.49 & 14.67 \\
\hline Unemployment Rate & 0.48 & -0.43 & -1.46 & -4.03 \\
\hline
\end{tabular}

\section{A.2.2 Replacement Ratio}

Next we present the results for the case where we set the value for the replacement ratio equal to 0.71, as estimated in Hall and Milgrom (2008), and then recalibrate the model to match all other parameters (only $c_{L}, c_{H}, h^{I}, y_{H}, b_{L}$ and $b_{H}$ change). 
Table A.6: Values of the Calibrated Parameters

\begin{tabular}{ll}
\hline Value & Interpretation \\
\hline \hline$c_{L}=0.900, c_{H}=3.143$ & Vacancy costs \\
$A_{L}=0.665, A_{H}=1.463$ & Matching efficiency parameters \\
$h^{I}=2.959$ & Search cost \\
$y_{H}=1.592$ & Relative productivity of high-skilled workers \\
$b_{L}=0.696, b_{H}=1.122$ & Unemployment flow incomes \\
$\gamma=0.077$ & Transferability of foreign human capital \\
\hline
\end{tabular}

Table A.7 presents the results regarding a movement from a no cross-skill matching to a cross-skill matching regime. The results are to be compared with those in Table 3 . As can be seen, the differences are qualitatively in the same direction and quantitatively small.

Table A.7: The Effects of Cross-skill Matching

\begin{tabular}{|c|c|}
\hline \multicolumn{2}{|c|}{ From No Cross-skill Matching to Cross-skill Matching } \\
\hline Value & \% Change \\
\hline \multicolumn{2}{|c|}{ Unskilled Natives } \\
\hline Wage $\left(w_{L L}^{N}\right)$ & 0.02 \\
\hline Unemployment Rate $\left(\frac{u_{L}^{N}}{1-\lambda}\right)$ & -0.99 \\
\hline Labor Market Tightness $\left(\theta_{L}\right)$ & 2.14 \\
\hline \multicolumn{2}{|c|}{$\begin{array}{ll}\text { Skilled Natives } \\
\end{array}$} \\
\hline Wage $\left(w_{H H}^{N}\right)$ & -0.12 \\
\hline Unemployment Rate $\left(\frac{u_{H}^{N}}{\lambda}\right)$ & 18.75 \\
\hline Labor Market Tightness $\left(\theta_{H}\right)$ & -29.60 \\
\hline \multicolumn{2}{|c|}{$\begin{array}{l}\text { Overall Natives } \\
\end{array}$} \\
\hline Wage & -0.08 \\
\hline Unemployment Rate & 3.51 \\
\hline Surplus1 & 0.01 \\
\hline Surplus2 & -0.06 \\
\hline \multicolumn{2}{|c|}{ Unskilled Immigrants } \\
\hline Wage $\left(w_{L L}^{I}\right)$ & 0.24 \\
\hline Unemployment Rate $\left(\frac{u_{L}^{I}}{I_{L}}\right)$ & -0.99 \\
\hline \multicolumn{2}{|c|}{$\begin{array}{l}\text { Skilled Immigrants } \\
\end{array}$} \\
\hline Wage $\left(w_{H H}^{I}\right)$ & 13.96 \\
\hline Employment Rate $\left(\frac{e_{H H}^{I}}{I_{H}}\right)$ & -3.68 \\
\hline \multicolumn{2}{|c|}{$\begin{array}{ll}\text { Overall Skilled Immigrants } \\
\end{array}$} \\
\hline Wage & 8.26 \\
\hline Unemployment Rate & -81.89 \\
\hline \multicolumn{2}{|c|}{$\begin{array}{ll}\text { Overall Immigrants } \\
\end{array}$} \\
\hline Wage & 3.62 \\
\hline Unemployment Rate & -51.31 \\
\hline
\end{tabular}

Table A.8 presents the effects of immigration influx. The results are to be compared 
with those in Table 4. As can be seen, the differences are qualitatively in the same direction and quantitatively small.

Table A.8: The Effects of the 2000-2009 Immigration Influx (Percentage Changes)

\begin{tabular}{|c|c|c|c|}
\hline Variable & $I_{L}$ & $I_{H}$ & $I_{L}$ and $I_{H}$ \\
\hline \multicolumn{4}{|c|}{ Unskilled Natives } \\
\hline Wage $\left(w_{L L}^{N}\right)$ & 0.19 & 0.01 & 0.19 \\
\hline Unemployment Rate $\left(\frac{u_{L}^{N}}{1-\lambda}\right)$ & -10.11 & -0.60 & -10.40 \\
\hline Labor Market Tightness $\left(\theta_{L}\right)$ & 25.37 & 1.30 & 26.26 \\
\hline \multicolumn{4}{|c|}{$\begin{array}{l}\text { Skilled Natives } \\
\end{array}$} \\
\hline Wage $\left(w_{H H}^{N}\right)$ & -0.00 & 0.05 & 0.05 \\
\hline Unemployment Rate $\left(\frac{u_{H}^{N}}{\lambda}\right)$ & 0.64 & -7.03 & -6.39 \\
\hline Labor Market Tightness $\left(\theta_{H}\right)$ & -1.29 & 16.07 & 14.45 \\
\hline \multicolumn{4}{|c|}{ Overall Natives } \\
\hline Wage & 0.04 & 0.04 & 0.08 \\
\hline Unemployment Rate & -7.22 & -2.33 & -9.32 \\
\hline Surplus1 & 0.86 & 0.30 & 1.14 \\
\hline Surplus2 & 1.17 & 0.37 & 1.51 \\
\hline \multicolumn{4}{|c|}{ Unskilled Immigrants } \\
\hline Wage $\left(w_{L L}^{I}\right)$ & 2.47 & 0.15 & 2.54 \\
\hline Unemployment Rate $\left(\frac{u_{L}^{I}}{I_{L}}\right)$ & -10.11 & -0.60 & -10.40 \\
\hline \multicolumn{4}{|c|}{ Skilled Immigrants } \\
\hline Wage $\left(w_{H H}^{I}\right)$ & 0.43 & 1.84 & 2.22 \\
\hline Employment Rate $\left(\frac{e_{H H}^{I}}{I_{H}}\right)$ & -0.15 & 1.67 & 1.52 \\
\hline Wage $\left(w_{H L}^{I}\right)$ & 1.93 & -0.70 & 1.23 \\
\hline Overeducation Ratio $\left(\frac{e_{H L}^{I}}{I_{H}}\right)$ & 1.94 & -6.35 & -4.44 \\
\hline \multicolumn{4}{|c|}{ Overall Skilled Immigrants } \\
\hline Wage & 0.57 & 1.80 & 2.31 \\
\hline Unemployment Rate $\left(\frac{u_{H}^{I}}{I_{H}}\right)$ & -9.03 & -2.17 & -10.72 \\
\hline \multicolumn{4}{|c|}{ Overall Immigrants } \\
\hline Wage & -0.36 & 4.31 & 2.97 \\
\hline Unemployment Rate & -3.07 & -10.75 & -10.63 \\
\hline
\end{tabular}

Table A.9 presents the effects from a change in the transferability of foreign human capital. The initial state is the one where $\gamma=0.077$ (overeducation ratio for high-skilled immigrants 20\%). The differences between Tables 5 and A.9 are qualitatively in the same direction and quantitatively small. 
Table A.9: The Effects of a Change in the Transferability of Human Capital (Percentage Changes)

\begin{tabular}{|c|c|c|c|c|}
\hline Variable & $\gamma=0.06$ & $\gamma=0.10$ & $\gamma=0.20$ & $\gamma=0.60$ \\
\hline Overeducation Ratio (\%) & 25.7 & 15.4 & 7.4 & 1.5 \\
\hline \multicolumn{5}{|c|}{ Unskilled Natives } \\
\hline Wage $\left(w_{L L}^{N}\right)$ & 0.00 & -0.00 & -0.01 & -0.02 \\
\hline Unemployment Rate $\left(\frac{u_{L}^{N}}{1-\lambda}\right)$ & -0.18 & 0.18 & 0.62 & 1.16 \\
\hline Labor Market Tightness $\left(\theta_{L}\right)$ & 0.37 & -0.38 & -1.31 & -2.43 \\
\hline \multicolumn{5}{|c|}{$\begin{array}{l}\text { Skilled Natives } \\
\end{array}$} \\
\hline Wage $\left(w_{H H}^{N}\right)$ & -0.03 & 0.02 & 0.02 & -0.10 \\
\hline Unemployment Rate $\left(\frac{u_{H}^{N}}{\lambda}\right)$ & 4.32 & -2.64 & -3.01 & 13.74 \\
\hline Labor Market Tightness $\left(\theta_{H}\right)$ & -8.28 & 5.63 & 6.44 & -23.19 \\
\hline \multicolumn{5}{|c|}{ Overall Natives } \\
\hline Wage & -0.02 & 0.01 & 0.01 & -0.08 \\
\hline Unemployment Rate & 1.03 & -0.58 & -0.35 & 4.54 \\
\hline Surplus1 & 0.01 & -0.02 & -0.13 & -0.37 \\
\hline Surplus2 & -0.01 & -0.01 & -0.13 & -0.50 \\
\hline \multicolumn{5}{|c|}{ Unskilled Immigrants } \\
\hline Wage $\left(w_{L L}^{I}\right)$ & 0.04 & -0.04 & -0.15 & -0.28 \\
\hline Unemployment Rate $\left(\frac{u_{L}^{I}}{I_{L}}\right)$ & -0.18 & 0.18 & 0.62 & 1.16 \\
\hline \multicolumn{5}{|c|}{ Skilled Immigrants } \\
\hline Wage $\left(w_{H H}^{I}\right)$ & -7.25 & 6.78 & 21.22 & 37.21 \\
\hline Employment Rate $\left(\frac{e_{H H}^{I}}{I_{H}}\right)$ & -7.30 & 6.03 & 16.72 & 25.58 \\
\hline Wage $\left(w_{H L}^{I}\right)$ & 2.88 & -3.35 & -13.85 & -35.64 \\
\hline Overeducation Ratio $\left(\frac{e_{H L}^{I}}{I_{H}}\right)$ & 28.31 & -23.15 & -63.10 & -92.64 \\
\hline \multicolumn{5}{|c|}{ Overall Skilled Immigrants } \\
\hline Wage & -6.58 & 6.78 & 23.20 & 37.21 \\
\hline Unemployment Rate & 6.40 & -6.16 & -21.67 & -52.35 \\
\hline \multicolumn{5}{|c|}{ Overall Immigrants } \\
\hline Wage & -2.28 & 2.38 & 8.10 & 15.19 \\
\hline Unemployment Rate & 0.48 & -0.43 & -1.45 & -3.87 \\
\hline
\end{tabular}

\section{A.2.3 Relative Search Cost}

In Tables A.10 and A.11 we present the results for the case where we change the value for the relative search cost parameter $\eta$ but keep all other parameter values the same. Table A.10 presents the effects of an immigration influx. These results are to be compared with those presented in Table 4 , where $\eta=0.5$. As can be seen, the differences are qualitatively in the same direction and quantitatively small. 
Table A.10: The Effects of the 2000-2009 Immigration Influx

$$
\eta=0.75
$$

(Percentage Changes)

\begin{tabular}{|c|c|c|c|}
\hline Variable & $I_{L}$ & $I_{H}$ & $I_{L}$ and $I_{H}$ \\
\hline \multicolumn{4}{|c|}{ Unskilled Natives } \\
\hline Wage $\left(w_{L L}^{N}\right)$ & 0.25 & -0.00 & 0.25 \\
\hline Unemployment Rate $\left(\frac{u_{L}^{N}}{1-\lambda}\right)$ & -7.89 & 0.09 & -7.72 \\
\hline Labor Market Tightness $\left(\theta_{L}\right)$ & 19.10 & -0.20 & 18.62 \\
\hline \multicolumn{4}{|c|}{ Skilled Natives } \\
\hline Wage $\left(w_{H H}^{N}\right)$ & -0.00 & 0.07 & 0.06 \\
\hline Unemployment Rate $\left(\frac{u_{H}^{N}}{\lambda}\right)$ & 0.26 & -5.46 & -5.18 \\
\hline Labor Market Tightness $\left(\theta_{H}\right)$ & -0.53 & 12.15 & 11.48 \\
\hline \multicolumn{4}{|c|}{$\begin{array}{ll}\text { Overall Natives } \\
\end{array}$} \\
\hline Wage & 0.10 & 0.04 & 0.13 \\
\hline Unemployment Rate & -5.85 & -1.30 & -7.08 \\
\hline Surplus1 & 0.97 & 0.31 & 1.26 \\
\hline Surplus2 & 1.15 & 0.33 & 1.46 \\
\hline \multicolumn{4}{|c|}{ Unskilled Immigrants } \\
\hline Wage $\left(w_{L L}^{I}\right)$ & 2.04 & -0.02 & 2.00 \\
\hline Unemployment Rate $\left(\frac{u_{L}^{I}}{I_{L}}\right)$ & -7.89 & 0.09 & -7.72 \\
\hline \multicolumn{4}{|c|}{ Skilled Immigrants } \\
\hline Wage $\left(w_{H H}^{I}\right)$ & 0.25 & 1.95 & 2.18 \\
\hline Employment Rate $\left(\frac{e_{H H}^{I}}{I_{H}}\right)$ & -0.06 & 1.21 & 1.14 \\
\hline Wage $\left(w_{H L}^{I}\right)$ & 0.99 & -0.44 & 0.56 \\
\hline Overeducation Ratio $\left(\frac{e_{H L}^{I}}{I_{H}}\right)$ & 1.39 & -5.12 & -3.73 \\
\hline \multicolumn{4}{|c|}{ Overall Skilled Immigrants } \\
\hline Wage & 0.34 & 1.69 & 2.18 \\
\hline Unemployment Rate $\left(\frac{u_{H}^{I}}{I_{H}}\right)$ & -7.02 & -1.21 & -8.01 \\
\hline \multicolumn{4}{|c|}{ Overall Immigrants } \\
\hline Wage & -0.19 & 3.41 & 2.40 \\
\hline Unemployment Rate & -0.81 & -10.34 & -8.34 \\
\hline
\end{tabular}

Table A.11 presents the results after a change in $\gamma$. In all cases, the initial situation is a value of $\gamma=0.077$ (overeducation ratio for high-skilled immigrants $18.5 \%$ ). The differences between Tables 5 and A.11 are qualitatively in the same direction and quantitatively small. 
Table A.11: The Effects of a Change in the Transferability of Human Capital (Percentage Changes)

\begin{tabular}{|c|c|c|c|c|}
\hline Variable & $\gamma=0.06$ & $\gamma=0.10$ & $\gamma=0.20$ & $\gamma=0.80$ \\
\hline Overeducation Ratio (\%) & 23.8 & 14.2 & 6.7 & 1.2 \\
\hline \multicolumn{5}{|c|}{ Unskilled Natives } \\
\hline Wage $\left(w_{L L}^{N}\right)$ & 0.00 & -0.00 & -0.01 & -0.01 \\
\hline Unemployment Rate $\left(\frac{u_{L}^{N}}{1-\lambda}\right)$ & -0.05 & 0.05 & 0.19 & 0.27 \\
\hline Labor Market Tightness $\left(\theta_{L}\right)$ & 0.12 & -0.12 & -0.41 & -0.57 \\
\hline \multicolumn{5}{|c|}{$\begin{aligned} \text { Skilled Natives } \\
\end{aligned}$} \\
\hline Wage $\left(w_{H H}^{N}\right)$ & -0.04 & 0.03 & 0.03 & -0.14 \\
\hline Unemployment Rate $\left(\frac{u_{H}^{N}}{\lambda}\right)$ & 3.69 & -2.20 & -2.22 & 11.40 \\
\hline Labor Market Tightness $\left(\theta_{H}\right)$ & -7.14 & 4.65 & 4.68 & -19.81 \\
\hline \multicolumn{5}{|c|}{ Overall Natives } \\
\hline Wage & -0.02 & 0.01 & 0.01 & -0.08 \\
\hline Unemployment Rate & 0.88 & -0.51 & -0.41 & 3.06 \\
\hline Surplus1 & 0.00 & -0.02 & -0.14 & -0.40 \\
\hline Surplus2 & -0.01 & -0.02 & -0.14 & -0.46 \\
\hline \multicolumn{5}{|c|}{ Unskilled Immigrants } \\
\hline Wage $\left(w_{L L}^{I}\right)$ & 0.01 & -0.01 & -0.05 & -0.07 \\
\hline Unemployment Rate $\left(\frac{u_{L}^{I}}{I_{L}}\right)$ & -0.05 & 0.05 & 0.19 & 0.27 \\
\hline \multicolumn{5}{|c|}{ Skilled Immigrants } \\
\hline Wage $\left(w_{H H}^{I}\right)$ & -10.10 & 9.33 & 28.81 & 49.45 \\
\hline Employment Rate $\left(\frac{e_{H H}^{I}}{I_{H}}\right)$ & -6.70 & 5.53 & 15.36 & 23.58 \\
\hline Wage $\left(w_{H L}^{I}\right)$ & 1.94 & -2.25 & -9.23 & -23.59 \\
\hline Overeducation Ratio $\left(\frac{e_{H L}^{I}}{I_{H}}\right)$ & 28.56 & -23.32 & -63.59 & -93.24 \\
\hline \multicolumn{5}{|c|}{ Overall Skilled Immigrants } \\
\hline Wage & -8.12 & 8.44 & 28.81 & 51.82 \\
\hline Unemployment Rate & 6.51 & -6.30 & -22.39 & -54.60 \\
\hline \multicolumn{5}{|c|}{ Overall Immigrants } \\
\hline Wage & -2.73 & 2.85 & 9.16 & 17.78 \\
\hline Unemployment Rate & 0.56 & -0.52 & -1.80 & -4.74 \\
\hline
\end{tabular}

Next we present the case where we set the value of the relative search cost parameter $\eta=0.75$ and then recalibrate the model to match all targets. Table A.3 presents the new parameter values (only the values of $c_{H}, c_{L}$, and $h^{I}$ change).

Table A.12: Values of the Calibrated Parameters

\begin{tabular}{ll}
\hline Value & Interpretation \\
\hline \hline$c_{L}=1.188, c_{H}=4.236$ & Vacancy costs \\
$A_{L}=0.665, A_{H}=1.463$ & Matching efficiency parameters \\
$h^{I}=3.004$ & Search cost \\
$y_{H}=1.579$ & Relative productivity of high-skilled workers \\
$b_{L}=0.484, b_{H}=0.779$ & Unemployment flow incomes \\
$\gamma=0.077$ & Transferability of foreign human capital \\
\hline
\end{tabular}

Table A.13 presents the effects of a change in immigration equal to that found in the 
data. The differences between Tables 4, A.10 and A.13 are qualitatively in the same direction and quantitatively small.

Table A.13: The Effects of the 2000-2009 Immigration Influx (Percentage Changes)

\begin{tabular}{|c|c|c|c|}
\hline Variable & $I_{L}$ & $I_{H}$ & $I_{L}$ and $I_{H}$ \\
\hline \multicolumn{4}{|c|}{ Unskilled Natives } \\
\hline Wage $\left(w_{L L}^{N}\right)$ & 0.26 & -0.00 & 0.25 \\
\hline Unemployment Rate $\left(\frac{u_{L}^{N}}{1-\lambda}\right)$ & -8.07 & 0.07 & -7.91 \\
\hline Labor Market Tightness $\left(\theta_{L}\right)$ & 19.57 & -0.14 & 19.13 \\
\hline \multicolumn{4}{|c|}{$\begin{array}{ll}\text { Skilled Natives } \\
\end{array}$} \\
\hline Wage $\left(w_{H H}^{N}\right)$ & -0.00 & 0.07 & 0.07 \\
\hline Unemployment Rate $\left(\frac{u_{H}^{N}}{\lambda}\right)$ & 0.26 & -5.55 & -5.27 \\
\hline Labor Market Tightness $\left(\theta_{H}\right)$ & -0.53 & 12.37 & 11.70 \\
\hline \multicolumn{4}{|c|}{ Overall Natives } \\
\hline Wage & 0.10 & 0.04 & 0.14 \\
\hline Unemployment Rate & -5.83 & -1.44 & -7.20 \\
\hline Surplus1 & 1.00 & 0.32 & 1.30 \\
\hline Surplus2 & 1.18 & 0.36 & 1.52 \\
\hline \multicolumn{4}{|c|}{ Unskilled Immigrants } \\
\hline Wage $\left(w_{L L}^{I}\right)$ & 2.17 & -0.02 & 2.13 \\
\hline Unemployment Rate $\left(\frac{u_{L}^{I}}{I_{L}}\right)$ & -8.07 & 0.07 & -7.91 \\
\hline \multicolumn{4}{|c|}{ Skilled Immigrants } \\
\hline Wage $\left(w_{H H}^{I}\right)$ & 0.29 & 2.19 & 2.46 \\
\hline Employment Rate $\left(\frac{e_{H H}^{I}}{I_{H}}\right)$ & -0.06 & 1.31 & 1.25 \\
\hline Wage $\left(w_{H L}^{I}\right)$ & 1.01 & -0.43 & 0.59 \\
\hline Overeducation Ratio $\left(\frac{e_{H L}^{I}}{I_{H}}\right)$ & 1.32 & -5.07 & -3.74 \\
\hline \multicolumn{4}{|c|}{ Overall Skilled Immigrants } \\
\hline Wage & 0.41 & 1.80 & 2.17 \\
\hline Unemployment Rate $\left(\frac{u_{H}^{I}}{I_{H}}\right)$ & -7.25 & -1.23 & -8.25 \\
\hline \multicolumn{4}{|c|}{ Overall Immigrants } \\
\hline Wage & 0.27 & 2.95 & 2.47 \\
\hline Unemployment Rate & -1.07 & -10.21 & -8.46 \\
\hline
\end{tabular}

Table A.14 presents the effects from a change in the transferability of foreign human capital. The initial state is the one where $\gamma=0.077$ (overeducation ratio for high-skilled immigrants 20\%). The differences between Tables 5, A.11 and A.14 are qualitatively in the same direction and quantitatively small. 
Table A.14: The Effects of a Change in the Transferability of Human Capital (Percentage Changes)

\begin{tabular}{l|r|r|r|r}
\hline Variable & $\gamma=0.06$ & $\gamma=0.10$ & $\gamma=0.20$ & $\gamma=0.80$ \\
\hline Overeducation Ratio $(\%)$ & 25.6 & 15.4 & 7.4 & 1.4 \\
\hline Unskilled Natives \\
\hline Wage $\left(w_{L L}^{N}\right)$ & 0.00 & -0.00 & -0.01 & -0.01 \\
\hline Unemployment Rate $\left(\frac{u_{L}^{N}}{1-\lambda}\right)$ & -0.06 & 0.06 & 0.20 & 0.31 \\
\hline Labor Market Tightness $\left(\theta_{L}\right)$ & 0.12 & -0.12 & -0.43 & -0.65 \\
\hline \multicolumn{5}{c}{ Skilled Natives } \\
\hline Wage $\left(w_{H H}^{N}\right)$ & -0.05 & 0.03 & 0.04 & -0.14 \\
\hline Unemployment Rate $\left(\frac{u_{H}^{N}}{\lambda}\right)$ & 3.97 & -2.43 & -2.86 & 10.53 \\
\hline Labor Market Tightness $\left(\theta_{H}\right)$ & -7.67 & 5.17 & 6.10 & -18.54 \\
\hline \multicolumn{5}{c}{ Overall Natives } \\
\hline Wage & -0.03 & 0.02 & 0.02 & -0.08 \\
\hline Unemployment Rate & 1.03 & -0.61 & -0.62 & 3.05 \\
\hline Surplus1 10.00 & -0.02 & -0.13 & -0.41 \\
\hline Surplus2 & -0.00 & -0.01 & -0.13 & -0.48 \\
\hline Unskilled Immigrants \\
\hline Wage $\left(w_{L L}^{I}\right)$ & 0.01 & -0.02 & -0.05 & -0.08 \\
\hline Unemployment Rate $\left(\frac{u_{L}^{I}}{I_{L}}\right)$ & -0.06 & 0.06 & 0.20 & 0.31 \\
\hline \multicolumn{5}{c|}{ Skilled Immigrants } \\
\hline Wage $\left(w_{H H}^{I}\right)$ & -11.21 & 10.46 & 32.55 & 56.27 \\
\hline Employment Rate $\left(\frac{e_{H H}^{I}}{I_{H}}\right)$ & -7.21 & 5.99 & 16.70 & 25.69 \\
\hline Wage $\left(w_{H L}^{I}\right)$ & 1.90 & -2.22 & -9.21 & -24.13 \\
\hline Overeducation Ratio $\left(\frac{e_{H L}^{I}}{I_{H}}\right)$ & 27.95 & -22.98 & -62.99 & -92.93 \\
\hline Overall Skilled Immigrants \\
\hline Wage & -8.41 & 8.99 & 30.85 & 57.31 \\
\hline Unemployment Rate & 6.44 & -6.21 & -21.88 & -53.29 \\
\hline Overall Immigrants \\
\hline Uage & -2.76 & 2.96 & 10.20 & 19.13 \\
\hline Unemployment Rate & 0.58 & -0.53 & -1.81 & -4.70 \\
\hline
\end{tabular}

